\title{
Attenuation of the upregulation of NF-אB and AP-1 DNA-binding activities induced by tunicamycin or hypoxia/reoxygenation in neonatal rat cardiomyocytes by SERCA2a overexpression
}

\author{
ZHIGANG QU ${ }^{1,2^{*}}, \mathrm{XIAOCHUN} \mathrm{LU}^{3^{*}}$, YAN QU $^{4}$, TIANQI TAO ${ }^{5}$, XIUHUA LIU ${ }^{5}$ and XIAOYING LI $^{3}$ \\ ${ }^{1}$ Medical School of Chinese PLA, Beijing 100853; ${ }^{2}$ Department of General Practice, \\ The 900th Hospital of The Joint Logistic Support Force, Fuzhou, Fujian 350025; \\ ${ }^{3}$ Department of Cardiology, The Second Medical Center, Chinese PLA General Hospital, Beijing 100853; \\ ${ }^{4}$ Department of Functional Examination, Penglai Traditional Chinese Medicine Hospital, Penglai, Shandong 265600; \\ ${ }^{5}$ Department of Pathophysiology, Chinese PLA General Hospital, Beijing 100853, P.R. China
}

Received August 1, 2020; Accepted March 29, 2021

DOI: $10.3892 / \mathrm{ijmm} .2021 .4946$

\begin{abstract}
The present study aimed to investigate the effects of the overexpression of sarco/endoplasmic reticulum $\mathrm{Ca}^{2+}$-ATPase (SERCA2a) on endoplasmic reticulum (ER) stress (ERS)-associated inflammation in neonatal rat cardiomyocytes (NRCMs) induced by tunicamycin (TM) or hypoxia/reoxygenation (H/R). The optimal multiplicity of infection (MOI) was $2 \mathrm{pfu} /$ cell. Neonatal Sprague-Dawley rat cardiomyocytes cultured in vitro were infected with
\end{abstract}

Correspondence to: Professor Xiaoying Li, Department of Cardiology, The Second Medical Center, Chinese PLA General Hospital, 28 Fuxing Road, Beijing 100853, P.R. China

E-mail: xyli301@163.com

Professor Xiuhua Liu, Department of Pathophysiology, Chinese PLA General Hospital, 28 Fuxing Road, Beijing 100853, P.R. China E-mail: xiuhualiu98@163.com

*Contributed equally

Abbreviations: AP-1, activator protein-1; ARCMs, adult rat cardiomyocytes; ATF6, activating transcription factor 6; BiP, immunoglobulin heavy chain-binding protein; CCK-8, Cell Counting Kit-8; C/EBP, CCAAT-enhancer-binding proteins; EGFP, enhanced green fluorescent protein; eIF2 $\alpha$, eukaryotic protein synthesis initiation factor 2; EMSA, electrophoretic mobility shift assay; EOR, endoplasmic reticulum overload response; ER, endoplasmic reticulum; ERS, endoplasmic reticulum stress; HF, heart failure; $\mathrm{H} / \mathrm{R}$, hypoxia/reoxygenation; IOD, integrated optical density; IRE1 $\alpha$, inositol-requiring $1 \alpha$; MOI, multiplicity of infection; NRCMs, neonatal rat cardiomyocytes; PERK, double-stranded RNA-dependent protein kinase (PKR)-like ER kinase; SERCA2a, sarco/endoplasmic reticulum $\mathrm{Ca}^{2+}$-ATPase; SR, sarcoplasmic reticulum; TM, tunicamycin; TNF- $\alpha$, tumor necrosis factor- $\alpha$; TUDCA, tauroursodeoxycholic acid; UPR, unfolded protein response; XBP1, X-box binding protein-1

Key words: endoplasmic reticulum stress, endoplasmic reticulum overload response, $\mathrm{NF}-\kappa \mathrm{B}, \mathrm{SERCA} 2 \mathrm{a}$, tunicamycin adenoviral vectors carrying SERCA2a or enhanced green fluorescent protein genes, the latter used as a control. At $48 \mathrm{~h}$ following gene transfer, the NRCMs were treated with TM $(10 \mu \mathrm{g} / \mathrm{ml})$ or subjected to H/R to induce ERS. The results of electrophoretic mobility shift assay (EMSA) revealed that overexpression of SERCA2a attenuated the upregulation of nuclear factor (NF)- $\mathrm{BB}$ and activator protein-1 (AP-1) DNA-binding activities induced by $\mathrm{TM}$ or $\mathrm{H} / \mathrm{R}$. Western blot analysis and semi-quantitative RT-PCR revealed that the overexpression of SERCA2a attenuated the activation of the inositol-requiring $1 \alpha$ (IRE1 $\alpha)$ signaling pathway and ERS-associated apoptosis induced by TM. The overexpression of SERCA2a also decreased the level of phospho-p65 (Ser536) in the nucleus, as assessed by western blot analysis. However, the overexpression of SERCA2a induced the further nuclear translocation of NF- $\mathrm{\kappa B}$ p 65 and higher levels of tumor necrosis factor (TNF)- $\alpha$ transcripts in the NRCMs, indicating the occurrence of the ER overload response (EOR). Therefore, the overexpression of SERCA2a has a 'double-edged sword' effect on ERS-associated inflammation. On the one hand, it attenuates ERS and the activation of the IRE1 $\alpha$ signaling pathway induced by TM, resulting in the attenuation of the upregulation of NF- $\mathrm{KB}$ and AP-1 DNA-binding activities in the nucleus, and on the other hand, it induces EOR, leading to the further nuclear translocation of NF- $\mathrm{kB}$ and the transcription of TNF- $\alpha$. The preceding EOR may precondition the NRCMs against subsequent ERS induced by TM. Further studies using adult rat cardiomyocytes are required to prevent the interference of EOR. The findings of the present study may enhance the current understanding of the role of SERCA2a in cardiomyocytes.

\section{Introduction}

Heart failure (HF) is becoming an increasingly serious public health concern (1). Despite recent advances in treatment, HF remains a fatal clinical syndrome. In the mouse, rat and human adult heart, sarco/endoplasmic reticulum $\mathrm{Ca}^{2+}$-ATPase (SERCA2a) is the major cardiac isoform, 
which pumps $\mathrm{Ca}^{2+}$ from the cytosol to the sarcoplasmic reticulum (SR) lumen utilizing the energy obtained by hydrolyzing ATP. HF is associated with the decreased expression and activity of SERCA2a (2-4). For this reason, SERCA2a has become an attractive target for the gene targeted therapy of HF. The abnormal calcium flux, and contraction and relaxation of cardiomyocytes in a failing heart may be improved by the transfer of SERCA2a (5). The improvement in cardiac contractility following SERCA2a transfer has been confirmed in a number of small and large animal models of HF induced by pressure overload, volume overload, ischemia, rapid ventricular pacing, or long-term isoproterenol stimulation. In a porcine volume-overload HF model (6), rAAV1-mediated intracoronary gene transfer in vivo has been reported to maintain the contractile function and improve cardiac remodeling. In both transgenic mice and rats, the overexpression of SERCA2 has been shown to enhance calcium transients, myocardial contractility and the relaxation in the absence or presence of pressure overload (7-12). In addition to its beneficial effects on myocardial contractility, the transfer of SERCA2 $a$ revives energy metabolism in the heart (13-15), decreases the $\mathrm{Ca}^{2+}$ leak from the SR (16), restores electrical stability (17), reduces arrhythmic aftercontractions (18), decreases ventricular arrhythmias $(16,19,20)$, suppresses cellular alternans (21) and increases coronary flow by activating endothelial nitric oxide synthase in endothelial cells (22). Moreover, the Calcium Upregulation by Percutaneous Administration of Gene Therapy in Cardiac Disease (CUPID) study demonstrated the safety of SERCA2 a therapy in patients with advanced HF and unraveled the benefits of this therapy (23-25). However, in the CUPID 2 study (26), AAV1-SERCA2a did not improve the clinical course of HF.

Misfolded proteins in the endoplasmic reticulum (ER) can induce the unfolded protein response (UPR). The UPR is composed of at least three branches (27). In resting cells, the three ER-located stress sensors, namely double-stranded RNA-dependent protein kinase (PKR)-like ER kinase (PERK), inositol-requiring $1 \alpha$ (IRE1 $\alpha)$, and activating transcription factor (ATF)6, are associated with immunoglobulin heavy chain-binding protein (BiP) and are maintained in an inactive state. In response to ER stress (ERS), PERK phosphorylates the $\alpha$ subunit of the eukaryotic protein synthesis initiation factor 2 (eIF $2 \alpha$ ), resulting in the inhibition of translation of the majority of mRNAs, but allowing for the translation of ATF4 mRNA. Under ERS conditions, IRE1 $\alpha$ autophosphorylates and activates its RNase activity, resulting in the splicing of $\mathrm{X}$-box binding protein-1 (XBP1) mRNA and the production of an active spliced XBP1 isoform. In parallel, following its release from BiP, ATF6 migrates to the Golgi apparatus, where it is cleaved by site-1 protease (S1P) and site-2 protease (S2P). The functional cleaved fragment of ATF6 is then released and migrates to the nucleus. The UPR leads to apoptosis when cells fail to address the protein folding defects and cannot re-establish homeostasis in the ER.

It has been shown that the UPR and nuclear factor $\kappa$-light-chain-enhancer of activated $B$ cells $(\mathrm{NF}-\kappa \mathrm{B})$ interact at multiple levels and are interconnected through the production of reactive oxygen species (ROS), the release of calcium ion from the ER, activation of $\mathrm{NF}-\kappa \mathrm{B}$ and $\mathrm{c}$-Jun N-terminal kinases $(\mathrm{JNK})$ and the induction of the acute-phase response (27). Under ERS conditions, the PERK-induced phosphorylation of eIF $2 \alpha$ inhibits the translation of nuclear factor of $\kappa$ light polypeptide gene enhancer in B-cells inhibitor- $\alpha(\mathrm{I} \kappa \mathrm{B} \alpha)$, decreasing the export of nuclear NF- $\kappa \mathrm{B}$ to the cytoplasm. In response to ERS, the phosphorylated cytoplasmic domain of IRE1 $\alpha$ recruits tumor necrosis factor- $\alpha$-receptor-associated factor 2 (TRAF2). The IRE1 $\alpha$-TRAF2 complex interacts with I $\mathrm{B}$ kinase (IKK) and/or JNK to activate these kinases. Activated IKK activates NF- $\kappa \mathrm{B}$ through phosphorylation of $\mathrm{I} \kappa \mathrm{B}$, initiating the degradation of I $\mathrm{B}$. Activated JNK activates the transcription factor activator protein-1 (AP-1) through phosphorylation. Activated NF- $\kappa \mathrm{B}$ and AP-1 translocate to the nucleus and induce the transcription of inflammation-related genes. ATF6 can activate $\mathrm{NF}-\kappa \mathrm{B}$ through the protein kinase $B$ (Akt) pathway. In addition, the ERS-triggered release of calcium from the ER and ROS can activate NF- $\kappa \mathrm{B}(28)$.

Liu et al (29) revealed that the cardiomyocyte-specific tamoxifen-inducible disruption of SERCA2 induced ER/SR structural changes, UPR and apoptosis. As also previously demonstrated, in a porcine myocardial ischemia model, the overexpression of SERCA2a significantly attenuated the activation of UPR and decreased ERS-associated apoptosis (30).

In the above context, it was hypothesized that the overexpression of SERCA2a could attenuate ERS by maintaining calcium homeostasis, thereby attenuating ERS-associated inflammation. The present study was thus conducted to explore this premise by overexpressing SERCA2a in neonatal rat cardiomyocytes (NRCMs).

\section{Materials and methods}

Cell culture and experimental protocol. All animal experiments were carried out in accordance with the Guide for the Care and Use of Laboratory Animals (8th Edition, 2011) of National Research Council (US) (31) and approved by the Institutional Animal Care and Use Committee (IACUC) of PLA General Hospital (approval no. 2013-x7-28). The NRCMs were isolated from 1-day-old Sprague-Dawley rats. Pups were anesthetized with 5\% isoflurane and sacrificed by cervical dislocation. Hearts were removed and immediately placed in cold phosphate-buffered saline $(\mathrm{NaCl} 136.75 \mathrm{mmol} / \mathrm{l}, \mathrm{KCl}$ $2.68 \mathrm{mmol} / 1, \mathrm{Na}_{2} \mathrm{HPO}_{4} 9.75 \mathrm{mmol} / 1, \mathrm{KH}_{2} \mathrm{PO}_{4} 1.47 \mathrm{mmol} / \mathrm{l}$, glucose $5.50 \mathrm{mmol} / \mathrm{l}, \mathrm{pH} 7.4)$. The ventricles were minced and digested with $0.15 \%$ trypsin for $6-10 \mathrm{~min}$ at $37^{\circ} \mathrm{C}$, and the supernatant was then transferred to a centrifuge tube containing Dulbecco's modified Eagle's medium (cat. no. 31600-034; Thermo Fisher Scientific, Inc.) supplemented with $10 \%$ fetal bovine serum (Shandong Yin Xiang Wei Ye Group Co., Ltd.), $100 \mathrm{IU} / \mathrm{ml}$ penicillin, and $100 \mu \mathrm{g} / \mathrm{ml}$ streptomycin (cat. no. 15140-122; Thermo Fisher Scientific, Inc.). The digestion was repeated $\sim 10$ times. Following centrifugation for $10 \mathrm{~min}$, the supernatant was aspirated off and the cell pellet was resuspended in complete culture medium. The suspended cells were plated and incubated in a $5 \% \mathrm{CO}_{2}, 37^{\circ} \mathrm{C}$ incubator for $1 \mathrm{~h}$. Thereafter, the culture medium containing non-adherent cells was collected, and these enriched cardiomyocytes were seeded in cell culture flasks with $0.1 \mathrm{mmol} / 1$ 5-bromo-2-deoxyuridine added to the medium to inhibit fibroblast proliferation. After two days, the cardiomyocytes were trypsinized and counted; the aliquots of cardiomyocyte 
suspension were then seeded. Following another day of culture, the cells were kept in serum-free medium overnight for cell cycle synchronization. On the following day, the NRCMs were infected with adenoviral vectors carrying human SERCA2a or enhanced green fluorescent protein (EGFP) gene at an MOI of $2 \mathrm{pfu} / \mathrm{cell}$ (unless otherwise stated), the latter used as a control. At $48 \mathrm{~h}$ following infection, the cells were subjected to the corresponding treatments. Both rAd-SERCA2a and rAd-EGFP were purchased from Beijing FivePlus Molecular Medicine Institute Co., Ltd.

In the ERS model induced by tunicamycin (TM), the NRCMs were assigned to one of the four groups: i) The vehicle control, dimethyl sulfoxide was added to the complete culture medium; ii) the TM group, the culture medium was changed to fresh complete culture medium with $10 \mu \mathrm{g} / \mathrm{ml} \mathrm{TM}$; iii) the $\mathrm{TM}+\mathrm{rAd}$-EGFP group, at $48 \mathrm{~h}$ following rAd-EGFP infection, the culture medium was changed to fresh complete culture medium with $10 \mu \mathrm{g} / \mathrm{ml} \mathrm{TM}$; and iv) the TM + rAd-SERCA2a group, at $48 \mathrm{~h}$ following rAd-SERCA2a infection, the culture medium was changed to fresh complete culture medium with $10 \mu \mathrm{g} / \mathrm{ml} \mathrm{TM}$.

In another ERS model induced by hypoxia/reoxygenation (H/R), following infection with adenoviral vectors for $48 \mathrm{~h}$, for the control group, the culture medium was replaced with fresh complete medium and the culture flask was maintained in a normal cell culture incubator with $95 \%$ air and $5 \% \mathrm{CO}_{2}$; by contrast, for the $\mathrm{H} / \mathrm{R}, \mathrm{H} / \mathrm{R}+\mathrm{rAd}-\mathrm{EGFP}$, and $\mathrm{H} / \mathrm{R}+\mathrm{rAd}-\mathrm{SERCA} 2 \mathrm{a}$ groups, the culture medium was replaced with fresh low-glucose DMEM medium (cat. no. 31600-034; Thermo Fisher Scientific, Inc.) without calf serum, and the flasks were transferred to a tri-gas incubator $\left(5 \% \mathrm{O}_{2}, 5 \% \mathrm{CO}_{2}\right.$, $90 \% \mathrm{~N}_{2}$ ) (Thermo Fisher Scientific, Inc.) for $8 \mathrm{~h}$, and then returned to a normal cell culture incubator for $16 \mathrm{~h}$, without changing the serum-free low-glucose DMEM medium.

Cell viability assessment. Cell viability was assessed using the Cell Counting Kit-8 (CCK-8; Dojindo Molecular Technologies, Inc.) according to the manufacturer's instructions. Briefly, to each well seeded with the cells, $10 \mu \mathrm{l}$ of CCK-8 solution was added, avoiding the formation of bubbles during the process. The plate was then incubated at $37^{\circ} \mathrm{C}$ for $1 \mathrm{~h}$. The absorbance of solution in each well was detected at $450 \mathrm{~nm}$ using a microplate reader (SN: 1106007713; Tecan Group Ltd.).

Lactate dehydrogenase $(\mathrm{LDH})$ activity assay. The extent of cellular injury was assessed by measuring the release of LDH in the culture medium using a commercial kit (JianCheng Bioengineering Institute). The LDH activity was quantified by measuring the level of pyruvic acid at $450 \mathrm{~nm}$ using a Tecan microplate reader.

Determination of the optimal multiplicity of infection (MOI). O'Donnell et al (32) found out that the exogenous expression of SERCA in the NRCMs reduced the viability of the cells, with cell floaters occurring even if the MOI was as low as $5 \mathrm{pfu} / \mathrm{cell}$. The apoptotic index in myocytes infected with adenoviral vectors carrying the wild-type SERCA1 gene was $7 \%$ at $2 \mathrm{pfu} / \mathrm{cell}$ and $31 \%$ at $10 \mathrm{pfu} / \mathrm{cell}$. The expression of exogenous SERCA and acceleration of $\mathrm{Ca}^{2+}$ transients could be achieved with minimal cell damage in rat myocytes when the MOI was in the range of 1 to $4 \mathrm{pfu} / \mathrm{cell}$. O'Donnell et al (32) also performed in situ immunofluorescence staining with specific antibodies against the exogenous SERCA1. It was found out that SERCA1 was densely packed within sarco/endoplasmic reticulum even in apparently normal cells. Severe structural changes occurred in cytopathic cells. It should be highlighted that both wild-type SERCA and inactive SERCA mutant produced cytotoxic effects. Thus, the investigators proposed that the dense accumulation of SERCA within a very limited sarco/endoplasmic reticulum space will disturb membrane structure and function and perturb calcium homeostasis (32). Therefore, the present study decided to perform a titration test on the MOIs in the NRCMs transfected with rAd-SERCA2a, with the expression level of SERCA2a, cell viability and LDH in the cell culture supernatant evaluated. The present study hoped to determine a certain MOI value, at which the high expression of SERCA2a could be achieved, while the cytotoxicity would be minimized to prevent the impact on cell inflammation.

Electrophoretic mobility shift assay (EMSA). Nuclear extracts were prepared using the NProtein Extraction kit (Exprogen Biotechnologies, Inc.). The sequences of the probes used for the assay were as follows: Ds-Bio-NF- $\kappa \mathrm{B}$ probe, Bio-5'-AGTTGAGGGGACTTTCCCAGGC-3'-Bio; Ds-Bio-AP1 probe, Bio-5'-CGCTTGATGAGTCAGCCG GAA-3'-Bio; Ds-Bio-OCT1 probe, Bio-5'-TGTCGAATG CAAATCACTAGAA-3'-Bio. EMSA was carried out using the BiotinLight ${ }^{\mathrm{TM}}$ Chemiluminescent EMSA kit (Exprogen Biotechnologies, Inc.) according to the instruction manual. Competition experiments with 100-fold excess of unlabeled probe used as a specific competitor were performed to confirm the specificity of protein-DNA binding. Antibodies against

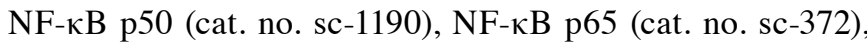
c-Jun (cat. no. sc-1694), and c-Fos (cat. no. sc-52) were purchased from Santa Cruz Biotechnology, Inc. A total of $4 \mu \mathrm{l}$ of undiluted antibodies were added to $15-\mu 1$ binding reactions. The samples were incubated for $20 \mathrm{~min}$ at room temperature. The sample was electrophoresed on a $1 \%$ agarose gel in $0.5 \mathrm{X}$ Tris-borate-EDTA buffer at $120 \mathrm{~V}$ for $1.5 \mathrm{~h}$, and then electrophoretically blotted onto a nylon membrane at $380 \mathrm{~mA}$ for $1 \mathrm{~h}$. The membrane was cross-linked in a UV-light cross-linker (Analytik Jena AG) for $10 \mathrm{~min}$, and the biotin-labeled DNA was detected by chemiluminescence.

Western blot analysis. Primary antibodies against BiP (cat. no. 3183; 1:1,000), phospho-PERK (cat. no. 3179; 1:1,000), PERK (cat. no. 3192; 1:1,000), phospho-eIF2 $\alpha$ (cat. no. 3398; $1: 1,000)$, eIF2 $\alpha$ (cat. no. 9722; 1:1,000), phospho-NF- $\kappa$ B p65 (Ser536) (cat. no. 3033; 1:1,000), NF-кB p65 (cat. no. 8242; 1:1,000), SERCA2 (cat. no. 9580; 1:1,000) and histone H3 (cat. no. 4499; 1:2,000) were purchased from Cell Signaling Technology, Inc., those against phospho-IRE1 (cat. no. ab48187; 1:1,000) and caspase-12 (cat. no. ab62484; 1:500) were from Abcam, that against IRE1 (cat. no. NB100-2324; 1:1,000) was from Novus Biologicals, LLC, that against CHOP (cat. no. sc-7351; 1:200) was from Santa Cruz Biotechnology, Inc. and that against GAPDH (cat. no. 60004-1-Ig; 1:2,000) was from Proteintech Group, Inc. HRP-conjugated secondary antibodies of goat anti-mouse IgG (cat. no. sc-2005; 1:3,000) 
and goat anti-rabbit $\operatorname{IgG}$ (cat. no. sc-2004; 1:3,000) were purchased from Santa Cruz Biotechnology, Inc. Whole-cell extracts were prepared using radioimmunoprecipitation assay lysis buffer (cat. no. CW2333; Beijing Cowinbioscience Co., Ltd.) containing a protease inhibitor cocktail (cat. no. CW2200; Beijing Cowinbioscience Co., Ltd.) and phosphatase inhibitors (cat. no. CW2383; Beijing Cowinbioscience Co., Ltd.). Cytoplasmic and nuclear extracts were prepared using the NE-PER ${ }^{\mathrm{TM}}$ Nuclear and Cytoplasmic Extraction Reagents (cat. no. 78833; Thermo Fisher Scientific, Inc.) according to the manufacturer's instructions. The protein concentration in each sample was determined using the BCA Protein Assay kit (cat. no. CW0014; Beijing Cowinbioscience Co., Ltd.) with bovine serum albumin as a standard. Equal amounts of protein $(100 \mu \mathrm{g})$ lysate per sample were denatured in 5X Sodium Dodecyl Sulfate-Polyacrylamide Gel Electrophoresis (SDS-PAGE) loading buffer (cat. no. CW0027; Beijing Cowinbioscience Co., Ltd.). Denatured proteins were separated on an $8-12 \%$ resolving gel and transferred onto nitrocellulose membranes (Pall Life Sciences) using a semidry transfer apparatus (Beijing Liuyi Biotechnology Co., Ltd.). After being blocked with 5\% bovine serum albumin (cat. no. 0332-100G; Amresco Inc.) in Tris-buffered saline with $0.1 \%$ Tween-20 (TBST) for $1 \mathrm{~h}$ at room temperature, the membranes were probed with primary antibodies with gentle agitation overnight at $4^{\circ} \mathrm{C}$. After washing with TBST buffer, the membranes were incubated with appropriate HRP-conjugated secondary antibodies at room temperature for $1 \mathrm{~h}$. After washing three times with TBST buffer, immunolabeled bands were detected by enhanced chemiluminescence. The integrated optical density (IOD) of the analyzed bands on the film was quantified using ImageJ software (National Institutes of Health; version 1.46). GAPDH and histone H3 served as cytoplasmic and nuclear internal controls, respectively. The levels of analyzed proteins were normalized to those of the internal control.

Semi-quantitative RT-PCR. Total RNA was isolated using the TRNzol method (cat. no. DP421; Tiangen Biotech Co., Ltd.). RNA ( $2 \mu \mathrm{g})$ was reverse transcribed with TransScript ${ }^{\circledR}$ First-Strand cDNA Synthesis SuperMix (cat. no. AT301; TransGen Biotech Co., Ltd.). The forward and reverse primers used for PCR were as follows: Tumor necrosis factor (TNF)- $\alpha$ forward, 5'-CGTAGCCCACGTCGTAGCAAA CCA-3' and reverse, 5'-CGCCAGTCGCCTCACAGAGCA AT-3'; XBP-1(u) forward, 5'-CTGGAGCAGCAAGTGGTG GATTT-3' and reverse, 5'-GTCCTTCTGGGTAGACCTCTG GGAG-3'; XBP1(s) forward, 5'-CTGAGTCCGCAGCAG GTGC-3' and reverse, 5'-CAGGGTCCAACTTGTCCAGAA TG-3'; GAPDH forward, 5'-TGCTGAGTATGTCGTGGAG-3' and reverse, 5'-GTCTTCTGAGTGGCAGTGAT-3'. The primers were purchased from Sangon Biotech Co., Ltd. The PCR reaction conditions were as follows: $94^{\circ} \mathrm{C}, 3 \mathrm{~min} ;\left(4^{\circ} \mathrm{C}\right.$, $\left.30 \mathrm{sec} ; 55^{\circ} \mathrm{C}, 30 \mathrm{sec} ; 72^{\circ} \mathrm{C}, 1 \mathrm{~min}\right) \times 30$ cycles; $72^{\circ} \mathrm{C}, 5 \mathrm{~min}$. The amplified products were separated on $1.5 \%$ agarose gels mixed with GoodView ${ }^{\mathrm{TM}}$ nucleic acid dye (cat. no. GV-2; Beijing SBS Genetech Co., Ltd.). Following electrophoresis, the agarose gel was visualized on a UV transilluminator and photographed. The IODs of the bands observed on the image were quantified using ImageJ software (National Institutes of
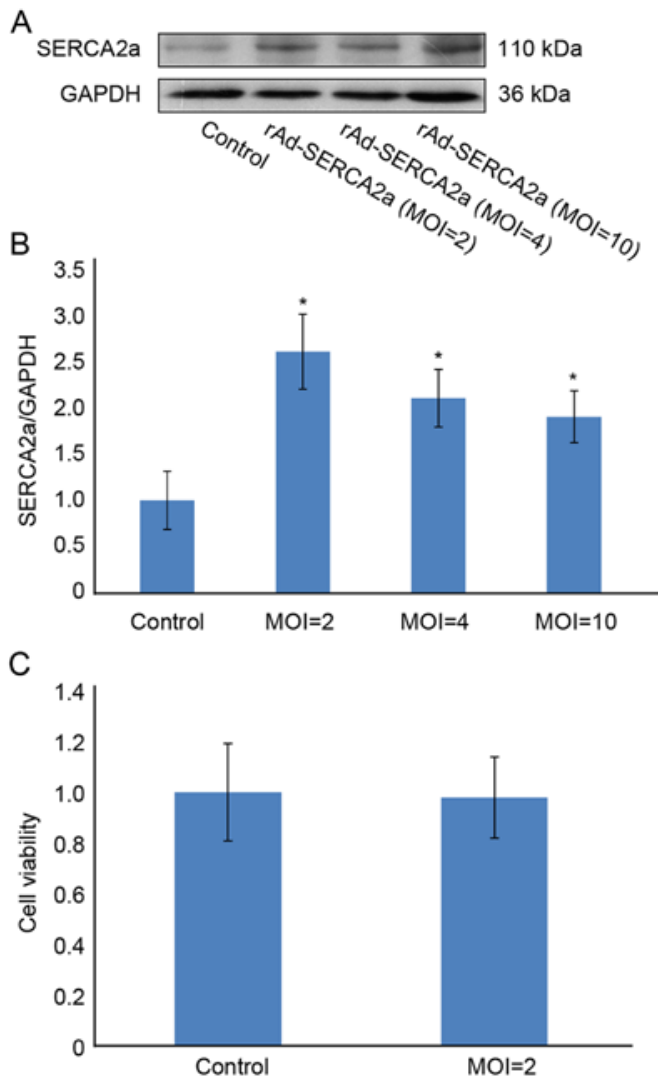

Figure 1. Protein levels of SERCA2a at the rAd-SERCA2a MOI of 2, 4 and $10 \mathrm{pfu} / \mathrm{cell}$. (A) Western blot bands corresponding to SERCA2a. (B) Bar graph showing the IODs of the SERCA2a bands from (A), quantified using ImageJ software, and normalized to GAPDH. The data are representative of three independent experiments (mean $\pm \mathrm{SD}$ ). (C) Cell viability at the rAd-SERCA2a MOI of $2 \mathrm{pfu} / \mathrm{cell}$. The data represent four independent experiments (mean $\pm \mathrm{SD}) .{ }^{*} \mathrm{P}<0.05$ vs. control. SERCA2a, sarco/endoplasmic reticulum $\mathrm{Ca}^{2+}$-ATPase; MOI, multiplicity of infection; IOD, integrated optical density.

Health; version 1.46). The transcription levels of the analyzed genes were normalized to those of GAPDH.

Statistical analysis. Data are expressed as the mean \pm SD. Statistical analyses of the data were carried out by one-way ANOVA, followed by post hoc Tukey's tests. A value of $\mathrm{P}<0.05$ was considered to indicate a statistically significant difference. All analyses were performed using SPSS 19.0 software (IBM, Inc.).

\section{Results}

Overexpression of SERCA2a attenuates the upregulation of nuclear NF- $\kappa B$ and AP-1 DNA-binding activities following treatment of NRCMs with TM. At MOIs of 2, 4 and $10 \mathrm{pfu} / \mathrm{cell}$, the expression level of SERCA2a was increased by 160,110 and $90 \%$, respectively, compared with that of the control group (Fig. 1). At an MOI of $2 \mathrm{pfu} / \mathrm{cell}$, the viability of the NRCMs was $97.8 \%$, similar to that of the control group. Unless otherwise stated, $2 \mathrm{pfu} / \mathrm{cell}$ was used as the preferred MOI in the subsequent experiments. When the MOI was $>2 \mathrm{pfu} / \mathrm{cell}$, the expression of SERCA2a was decreased, suggesting that the overexpression of SERCA2a may be cytotoxic. Following treatment with TM for $24 \mathrm{~h}$, the DNA-binding activity of NF- $\mathrm{KB}$ in the TM group was increased by 4.1 -fold $(\mathrm{P}<0.01$; Fig. 2). 
A

A

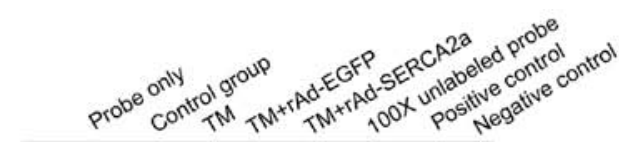

D
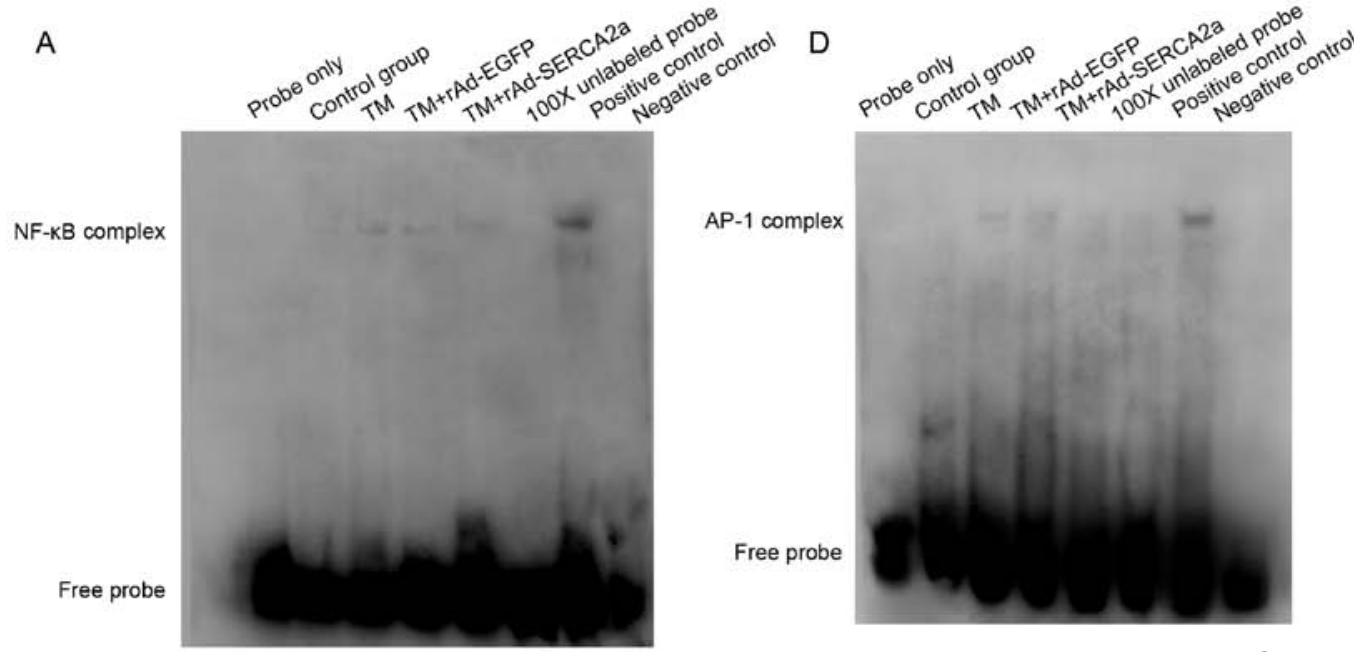

AP-1 complex

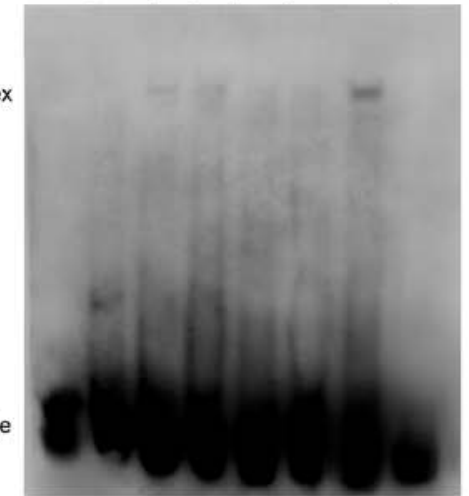

B

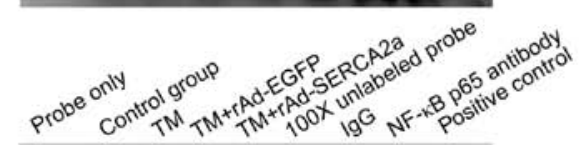

Free probe
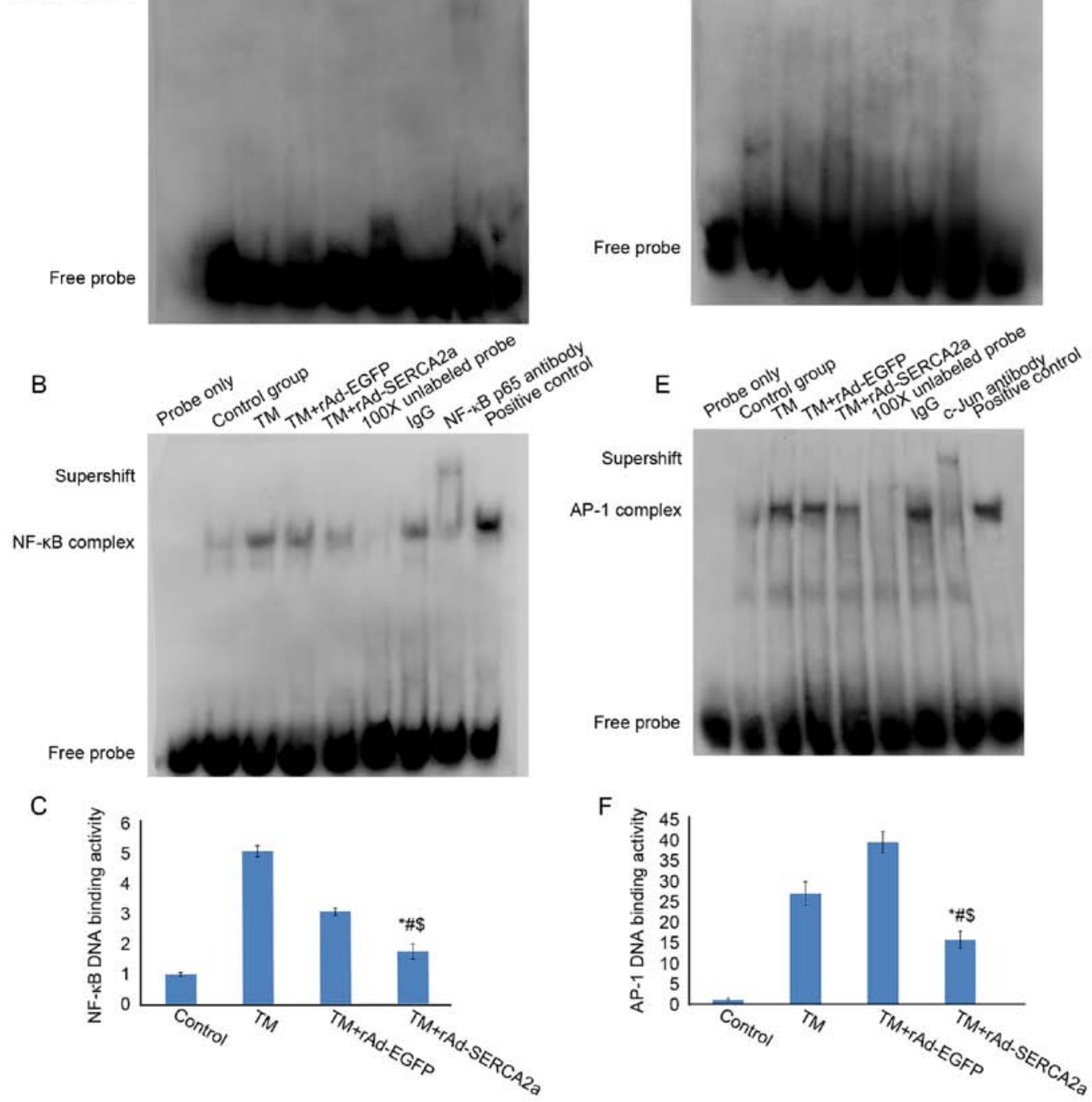

Figure 2. Effects of the overexpression of SERCA2a on the nuclear NF- $\mathrm{kB}$ and AP-1 DNA-binding activities in NRCMs following treatment with TM for 8 and $24 \mathrm{~h}$, as assessed by EMSA. (A) EMSA gel showing the NF-кB DNA-binding activity following treatment with TM for $8 \mathrm{~h}$. The amount of nuclear extract loaded was $3.5 \mu \mathrm{g}$. The eight lanes from left to right represent the following: Blank control (probe only), vehicle control group (Control), tunicamycin group (TM), tunicamycin + rAd-EGFP group (TM + rAd-EGFP), tunicamycin + rAd-SERCA2a group (TM + rAd-SERCA2a), 100X cold probe, positive control and negative control, respectively. (B) EMSA gel showing the NF-кB DNA-binding activity following treatment with TM for $24 \mathrm{~h}$. The amount of nuclear extract loaded was $10 \mu \mathrm{g}$. The nine lanes from left to right represent the blank control (probe only), vehicle control group (Control), TM, TM + rAd-EGFP, TM + rAd-SERCA2a, $100 X$ cold probe, non-specific IgG antibody, NF- $\mathrm{BB}$ p65 antibody and positive control, respectively. (C) The NF- $\mathrm{kB}$ complex bands from panel B were analyzed by densitometry using ImageJ software. (D) EMSA gel showing the AP-1 DNA-binding activity following treatment with TM for $8 \mathrm{~h}$. The amount of nuclear extract loaded was $3.5 \mu \mathrm{g}$. (E) EMSA gel showing the AP-1 DNA-binding activity following treatment with TM for $24 \mathrm{~h}$. The amount of nuclear extract loaded was $10 \mu \mathrm{g}$. (F) The AP-1 complex bands from panel E were analyzed by densitometry using ImageJ software. Data are representative of three independent experiments (mean $\pm \mathrm{SD}$ ). ${ }^{*} \mathrm{P}<0.01$ vs. TM + rAd-EGFP; ${ }^{4} \mathrm{P}<0.01$ vs. TM; ${ }^{{ }^{\mathrm{P}}} \mathrm{P}<0.05$ vs. Control. SERCA2a, sarco/endoplasmic reticulum Ca ${ }^{2+}$-ATPase; AP-1, activator protein-1; NRCMs, neonatal rat cardiomyocytes; TM, tunicamycin; EMSA, electrophoretic mobility shift assay; EGFP, enhanced green fluorescent protein.

Compared with the TM + rAd-EGFP and TM groups, the DNA-binding activity of $\mathrm{NF}-\kappa \mathrm{B}$ in the $\mathrm{TM}+\mathrm{rAd}-\mathrm{SERCA} 2 \mathrm{a}$ group was decreased by $43.6 \%(\mathrm{P}<0.01)$ and $66.0 \%(\mathrm{P}<0.01)$, respectively. Following treatment with TM for $24 \mathrm{~h}$, the DNA-binding activity of AP-1 in the TM group was increased by 26.9 -fold $(\mathrm{P}<0.01)$. Compared with the TM + rAd-EGFP and TM groups, the DNA-binding activity of AP-1 in the $\mathrm{TM}+\mathrm{rAd}-\mathrm{SERCA} 2 \mathrm{a}$ group was decreased by $60.2 \%(\mathrm{P}<0.01)$ and $26.3 \%(\mathrm{P}<0.01)$, respectively.
Overexpression of SERCA2a at an MOI of 1 pfu/cell still attenuates the upregulation of nuclear $N F-\kappa B$ and $A P-1$ DNA-binding activities following treatment of NRCMs with $T M$. As previously demonstrated, under limited exposure to calf serum, compared with the non-infected control group, the size, protein content and protein synthesis rate in the infected rat myocytes exhibited a more rapid increase (32). Tauroursodeoxycholic acid (TUDCA), a recognized ERS inhibitor, was used as a control in this experiment. The 


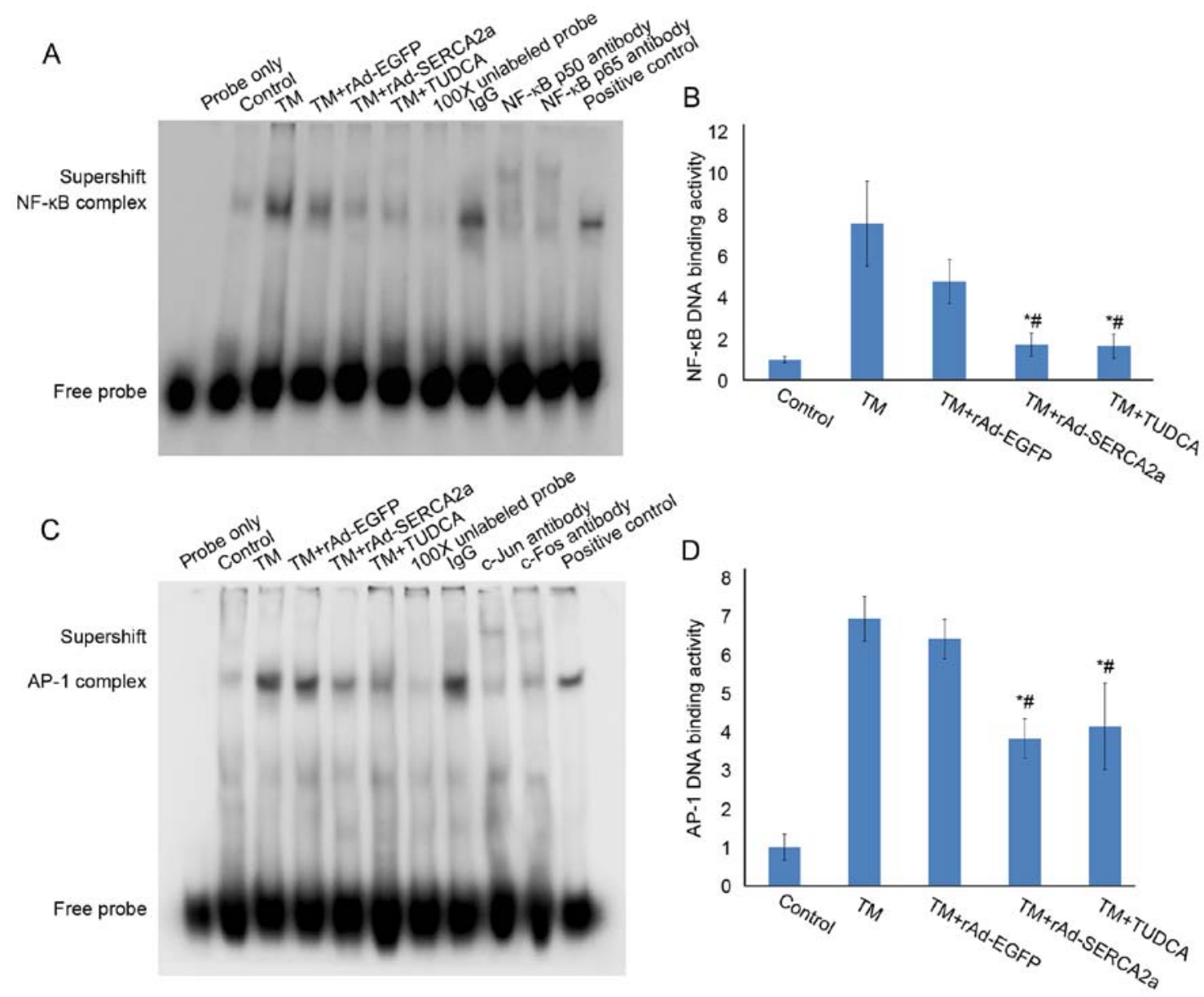

Figure 3. Effects of overexpression of SERCA2a at 1 pfu/cell on the NF- $\mathrm{kB}$ and AP-1 DNA-binding activities in NRCMs following treatment with TM for $24 \mathrm{~h}$ when the synchronization time was delayed to that prior to treatment with TM. (A) EMSA gel showing the NF- $\mathrm{BB}$ DNA-binding activity. The lanes from left to right represent the following: Blank control (probe only), vehicle control group (Control), TM, TM + rAd-EGFP, TM + rAd-SERCA2a, TM + TUDCA (500 $\mu \mathrm{mol} / 1), 100 \mathrm{X}$

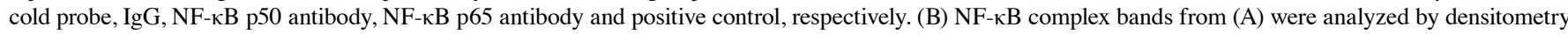
using ImageJ software. (C) EMSA gel showing the AP-1 DNA-binding activity. The lanes from left to right represent blank control (probe only), vehicle control (Control), TM, TM + rAd-EGFP, TM + rAd-SERCA2a, TM + TUDCA, 100X cold probe, IgG, c-Jun antibody, c-Fos antibody and positive control, respectively. (D) The AP-1 complex bands from panel $\mathrm{C}$ were analyzed by densitometry using ImageJ software. Data are representative of three independent experiments (mean $\pm \mathrm{SD}$ ). ${ }^{*} \mathrm{P}<0.05$ vs. TM + rAd-EGFP; ${ }^{*} \mathrm{P}<0.05$ vs. TM. SERCA2a, sarco/endoplasmic reticulum $\mathrm{Ca}^{2+}$-ATPase; AP-1, activator protein-1; NRCMs, neonatal rat cardiomyocytes; TM, tunicamycin; EMSA, electrophoretic mobility shift assay; EGFP, enhanced green fluorescent protein; TUDCA, tauroursodeoxycholic acid.

synchronization time was delayed to that prior to the addition of TM (final concentration, $10 \mu \mathrm{g} / \mathrm{ml}$ ), instead of that prior to infection. Considering that NRCMs are prone to the ER overload response (EOR) induced by rAd-SERCA2a infection, the MOI was reduced to $1.0 \mathrm{pfu} / \mathrm{cell}$. Compared with the TM + rAd-EGFP and TM groups, the overexpression of SERCA2a significantly attenuated the upregulation of NF- $\kappa \mathrm{B}$ (both $\mathrm{P}<0.05$ ) and the AP-1 DNA-binding activities (both $\mathrm{P}<0.05$ ), respectively. The results were similar to those observed at 2 pfu/cell (Fig. 3). The results of EMSA revealed that TUDCA significantly attenuated the upregulation of $\mathrm{NF}-\kappa \mathrm{B}$ and AP-1 DNA-binding activities induced by TM, corroborating the successful construction of the cellular model of ERS. The supershift assays revealed that activated $\mathrm{NF}-\kappa \mathrm{B}$ in the nucleus contained p50 and p65 subunits, and activated AP-1 in the nucleus contained c-Jun and c-Fos subunits (Fig. 3).

Overexpression of SERCA2a attenuates the upregulation of nuclear NF- $\kappa B$ and AP-1 DNA-binding activities induced by $H / R$. In the H/R model, the overexpression of SERCA2a significantly attenuated the upregulation of $N F-\kappa B$ and
AP-1 DNA-binding activities (Fig. 4), similar to the findings observed with the TM model.

Overexpression of SERCA2 a attenuates the activation of the IRE1 $\alpha$ signaling pathway induced by TM in the NRCMs. Compared with the vehicle control group, the protein levels of phospho-PERK (Thr980) (Fig. 5), phospho-IRE1 (Ser724) (Fig. 6), BiP, CHOP and cleaved caspase-12 (Fig. 7) in the TM group were significantly increased. No significant decreases were observed in the phospho-PERK (Thr980) and phospho-eIF2 $\alpha$ (Ser51) levels in the TM + rAd-SERCA2a group compared with the TM + rAd-EGFP group (Fig. 5). Compared with the TM + rAd-EGFP and TM groups, the ratio of phospho-IRE1 to unphosphorylated IRE1 in the $\mathrm{TM}+$ rAd-SERCA2a group was decreased by $25 \%(\mathrm{P}<0.01)$ and $31.8 \%(\mathrm{P}<0.01)$, respectively (Fig. 6). The results of semi-quantitative RT-PCR revealed that compared with the $\mathrm{TM}+$ rAd-EGFP and TM groups, the ratio of spliced active XBP1 to unspliced inactive XBP1 in the TM + rAd-SERCA2a $(\mathrm{MOI}=2.0)$ group was reduced by $20.5 \%(\mathrm{P}<0.01)$ and $20 \%$ $(\mathrm{P}<0.05)$, respectively. 

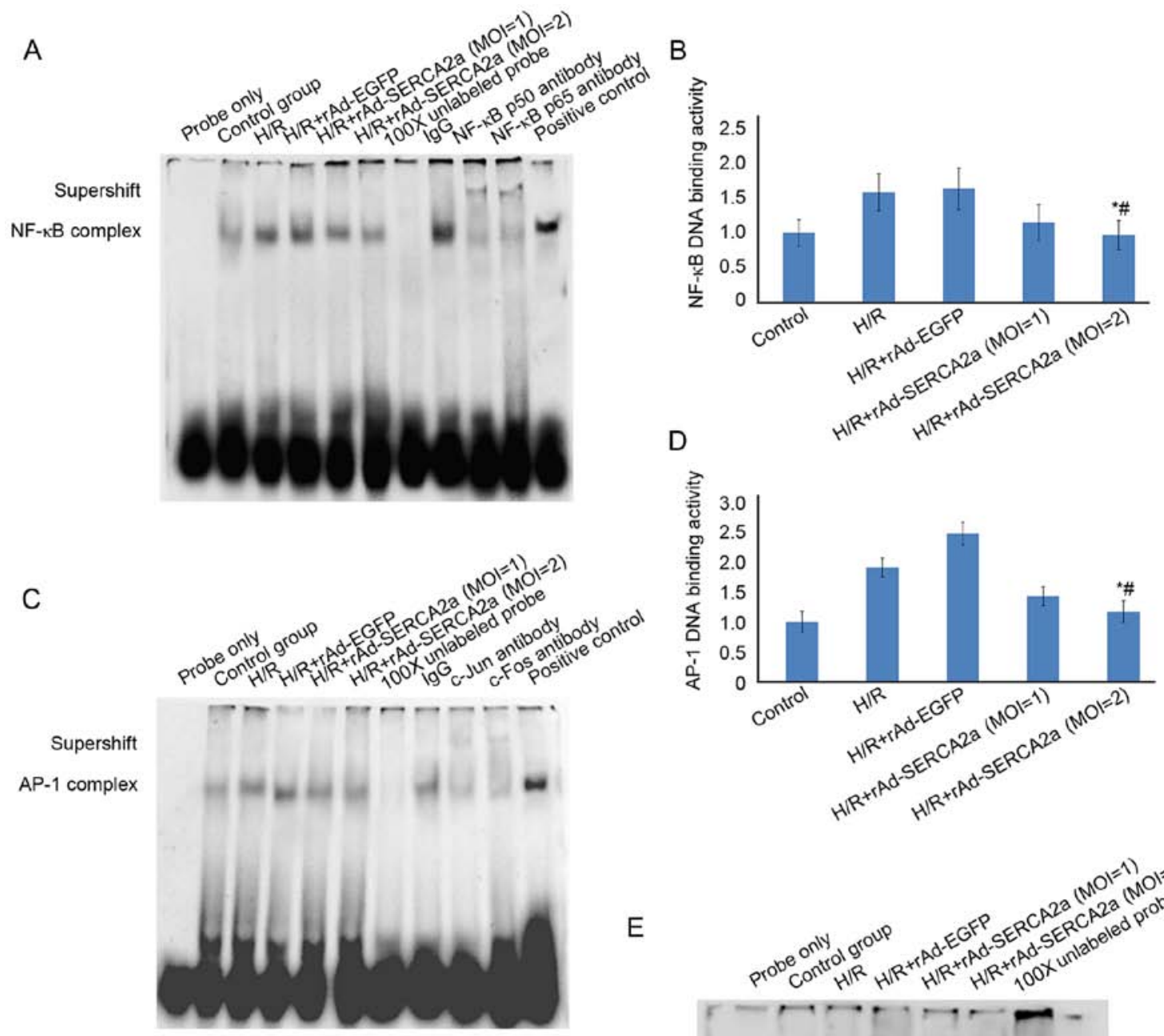

Oct-1 complex

Figure 4. Effects of the overexpression of SERCA2a on the NF- $\mathrm{B}$ and AP-1 DNA-binding activities in the other ERS model induced by H/R. (A) EMSA gel showing the NF- $\mathrm{B}$ DNA-binding activity following exposure to H/R for $24 \mathrm{~h}$. (B) NF- $\mathrm{B}$ complex bands from (A) were analyzed by densitometry using ImageJ software. (C) EMSA gel showing the AP-1 DNA-binding activity following exposure to H/R for $24 \mathrm{~h}$. (D) AP-1 complex bands from (C) were analyzed by densitometry. (E) Oct-1 was used as a control. Three independent experiments were performed (mean $\pm \mathrm{SD}$ ). ${ }^{*} \mathrm{P}<0.05 \mathrm{vs}$. $\mathrm{H} / \mathrm{R}+\mathrm{rAd}-\mathrm{EGFP} ;{ }^{\prime} \mathrm{P}<0.05 \mathrm{vs}$. H/R. SERCA2a, sarco/endoplasmic reticulum $\mathrm{Ca}^{2+}$-ATPase; AP-1, activator protein-1; EGFP, enhanced green fluorescent protein; ERS, endoplasmic reticulum stress; EMSA, electrophoretic mobility shift assay; H/R, hypoxia/reoxygenation.

Overexpression of SERCA2 a attenuates ERS-associated apoptosis. BiP, also known as Grp78, is one of the molecular markers of ERS. The overexpression of SERCA2a decreased the expression of BiP, compared with that in the $\mathrm{TM}+$ rAd-EGFP group. CHOP (also known as GADD153) and caspase-12 are relevant to ERS-associated apoptosis. Compared with the TM + rAd-EGFP group, the expression of $\mathrm{CHOP}$ and the ratio of cleaved caspase-12 to pro-caspase-12 in the TM + rAd-SERCA2a group were decreased by $40 \%$ $(\mathrm{P}<0.05)$ and $56 \%(\mathrm{P}<0.01)$, respectively (Fig. 7). Compared with the TM group, the expression of CHOP and the ratio of cleaved caspase-12 to pro-caspase-12 were decreased by $23 \%$ $(\mathrm{P}>0.05)$ and $3.9 \%(\mathrm{P}>0.05)$, respectively. These findings indicated that the overexpression of SERCA2a attenuated ERS-associated apoptosis.

Overexpression of SERCA2a induces EOR. The overexpression of molecules resident in the ER can lead to EOR. EOR is characterized by $N F-\kappa B$ activation. In the $\mathrm{TM}+\mathrm{rAd}-\mathrm{SERCA} 2 \mathrm{a}$ group, the nuclear translocation of $\mathrm{NF}-\kappa \mathrm{B}$ was significantly increased by 1.40 -fold $(\mathrm{P}<0.05)$, the transcription level of TNF- $\alpha$ increased by $87.4 \%(\mathrm{P}<0.05)$ 

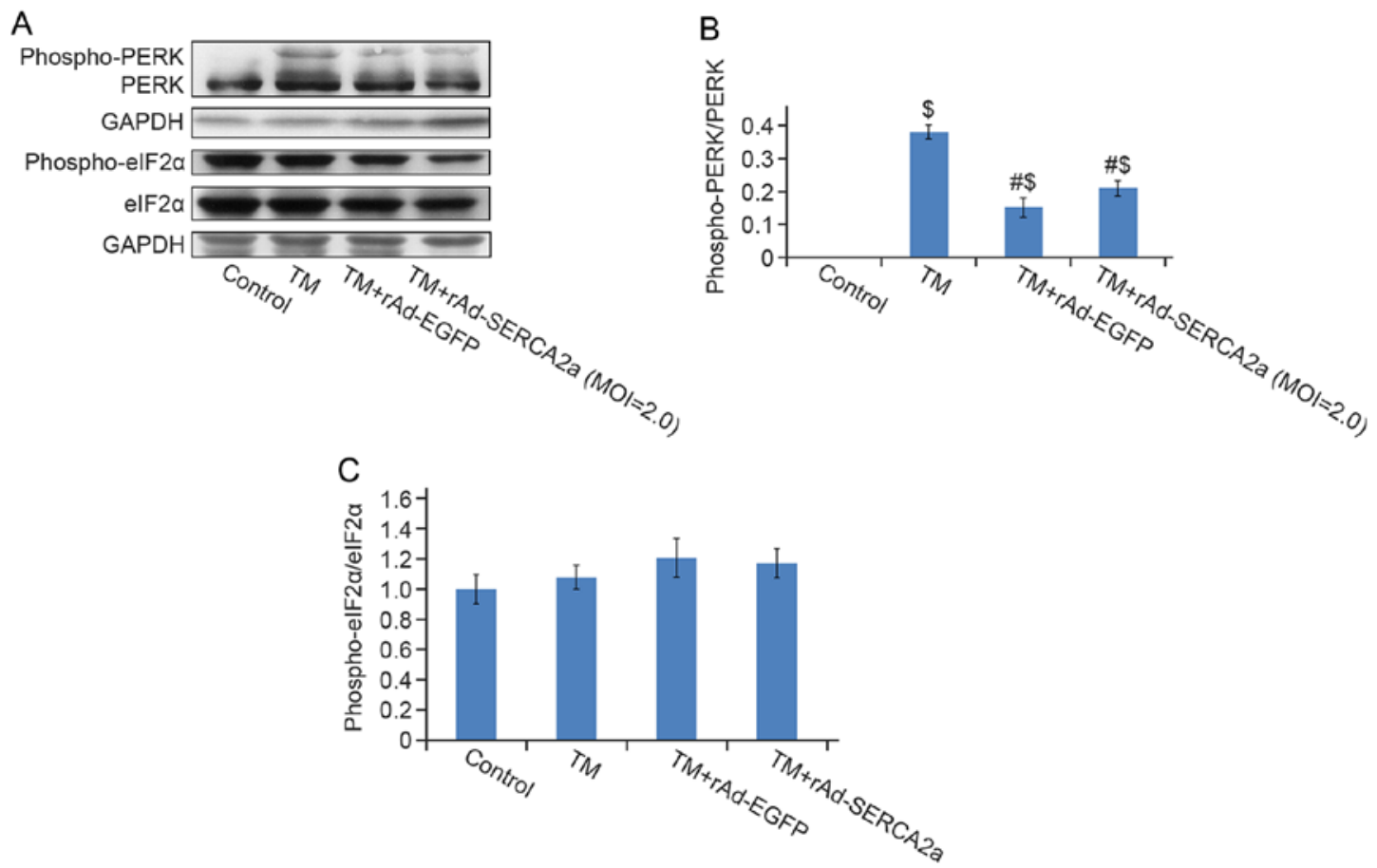

Figure 5. Effects of the overexpression of SERCA2a on the activation of the PERK signaling pathway following treatment with TM for $24 \mathrm{~h}$. (A) Western blot bands corresponding to phospho-PERK, unphosphorylated PERK, phospho-eIF2 $\alpha$, and eIF2 $\alpha$. GAPDH was used as an internal control. (B) Bar graph showing the ratio of the IODs of bands corresponding to phospho-PERK from (A) to that of unphosphorylated PERK. (C) Bar graph showing the ratio of the IODs of bands corresponding to phospho-eIF2 $\alpha$ from (A) to that of eIF2 $\alpha$. Data are representative of three independent experiments (mean \pm SD). ${ }^{\# P}<0.05$ vs. TM; ${ }^{\$} \mathrm{P}<0.01$ vs. Control. SERCA2a, sarco/endoplasmic reticulum $\mathrm{Ca}^{2+}$-ATPase; PERK, double-stranded RNA-dependent protein kinase (PKR)-like ER kinase; TM, tunicamycin; eIF2 $\alpha$, eukaryotic protein synthesis initiation factor 2; IOD, integrated optical density.

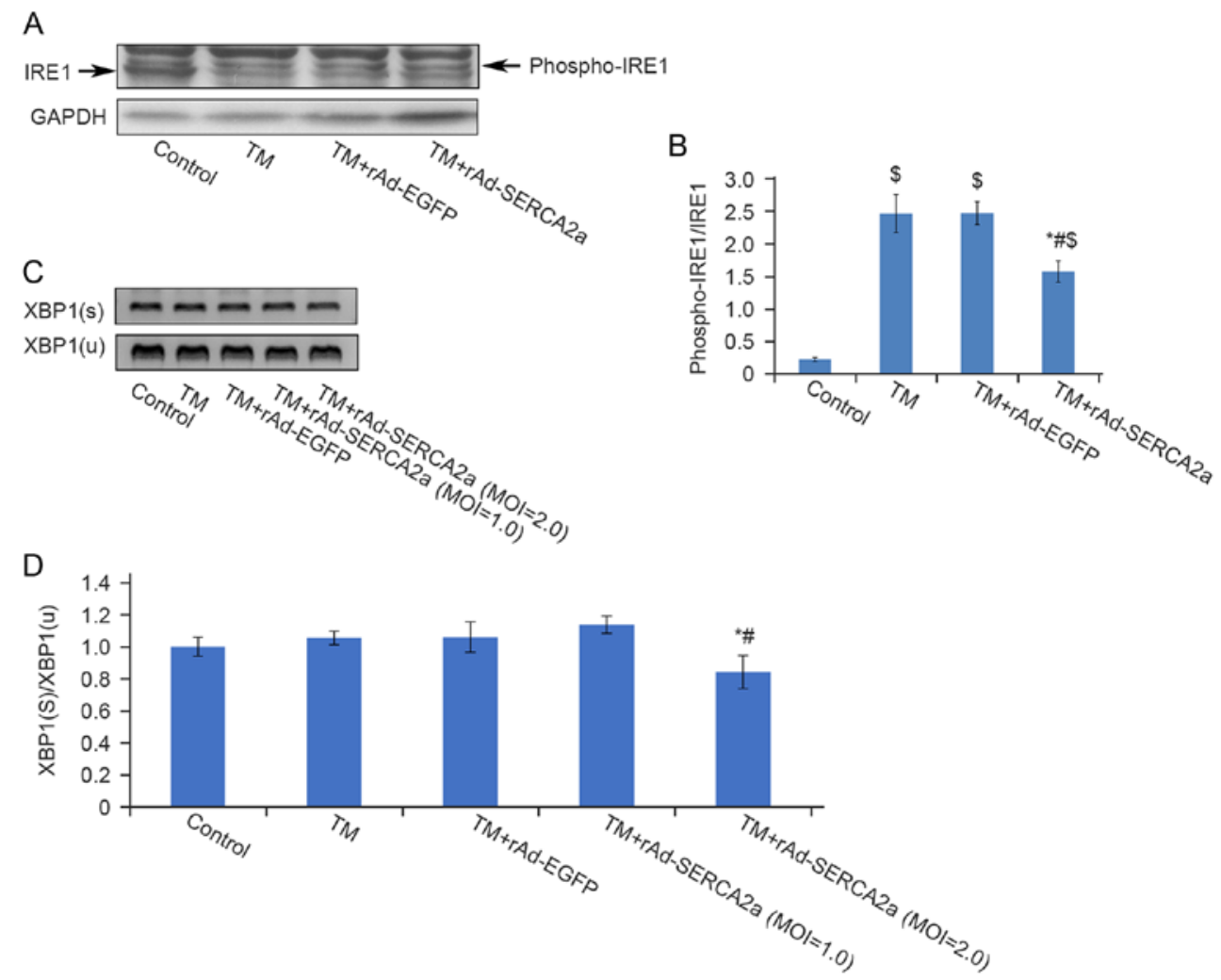

Figure 6. Effects of the overexpression of SERCA2a on the activation of the IRE1 $\alpha$ signaling pathway following treatment with TM. (A) Western blot bands corresponding to phospho-IRE1 and unphosphorylated IRE1. (B) Bar graph showing the ratio of the IODs of bands corresponding to phospho-IRE1 from (A) to that of unphosphorylated IRE1. (C) RT-PCR products corresponding to XBP1(s) and XBP1(u) following agarose gel electrophoresis. (D) Bar graph showing the ratio of the IODs of bands corresponding to XBP1(s) from (C) to that of XBP1(u). Data are representative of three independent experiments (mean \pm SD). ${ }^{*} \mathrm{P}<0.05$ vs. TM + rAd-EGFP; ${ }^{\#} \mathrm{P}<0.05$ vs. TM; ${ }^{\mathrm{P}} \mathrm{P}<0.01$ vs. Control. SERCA2a, sarco/endoplasmic reticulum $\mathrm{Ca}^{2+}$-ATPase; IRE1 $\alpha$, inositol-requiring $1 \alpha$; $\mathrm{TM}$, tunicamycin; IOD, integrated optical density; XBP1, X-box binding protein-1; EGFP, enhanced green fluorescent protein. 
A
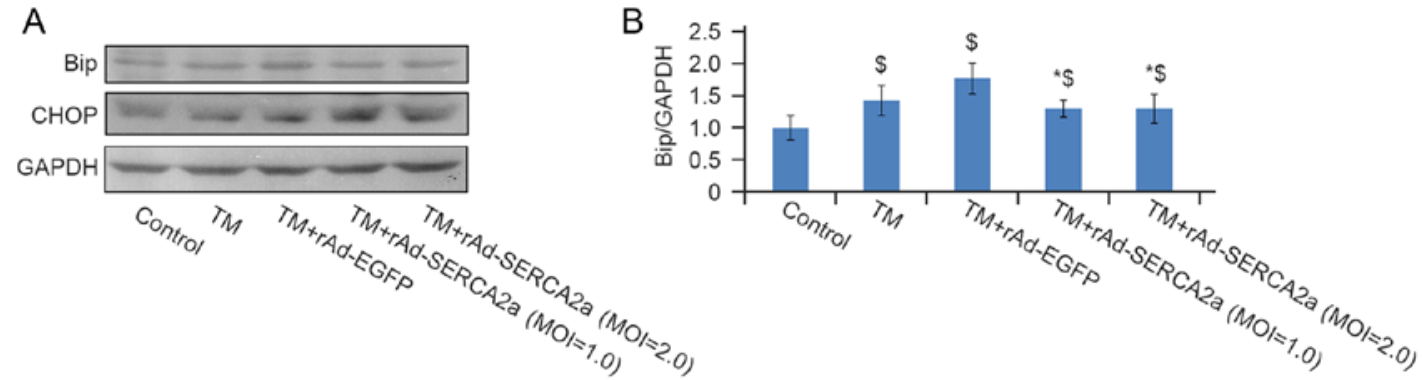

C
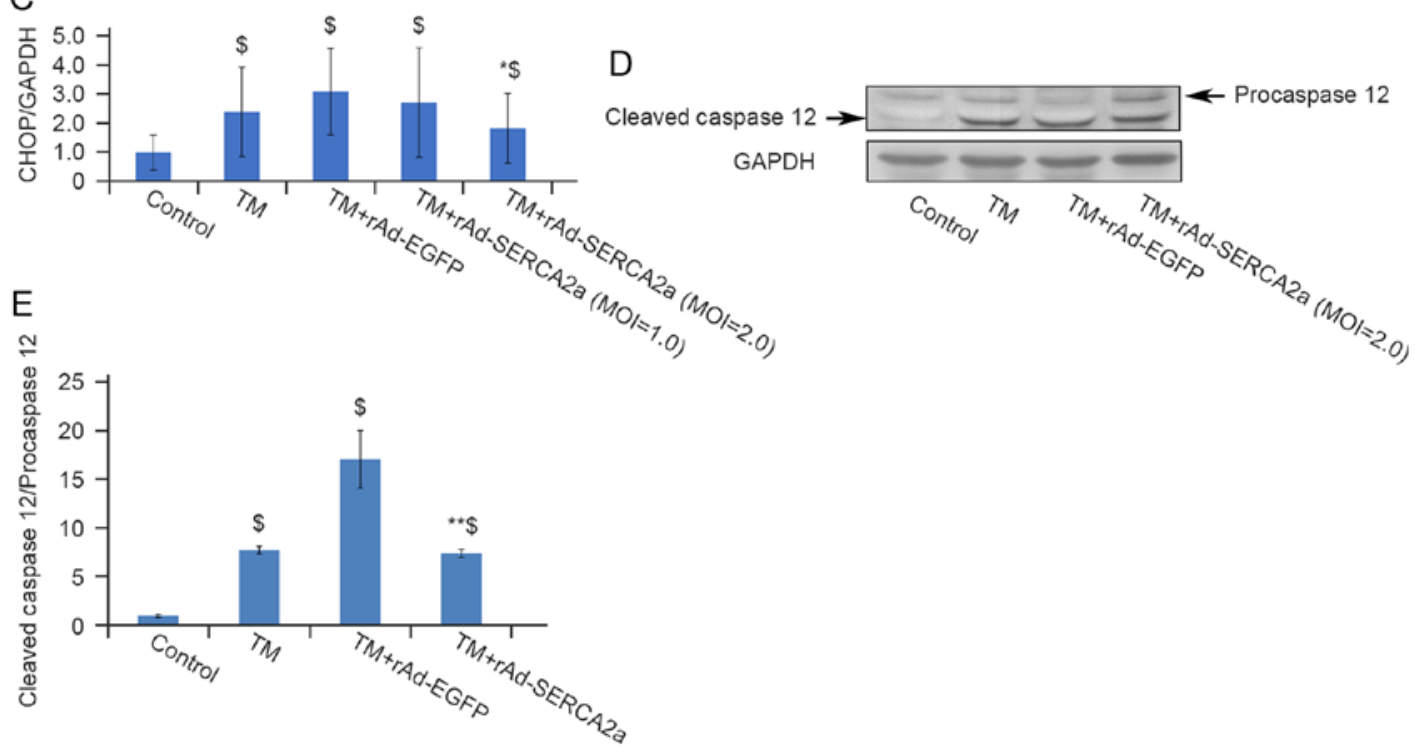

Figure 7. Effects of the overexpression of SERCA2a on ERS-associated apoptosis in NRCMs following treatment with TM for 24 h. (A) Western blot bands corresponding to BiP and CHOP. GAPDH was used as an internal control. (B) Bar graph showing the IODs of bands corresponding to BiP from (A) normalized to that of GAPDH. (C) Bar graph showing the IODs of bands corresponding to CHOP from (A) normalized to that of GAPDH. (D) Western blot bands corresponding to cleaved caspase-12 and pro-caspase-12. (E) Bar graph showing the ratio of the IODs of bands corresponding to cleaved caspase-12 from (D) to that of pro-caspase-12. Data are representative of three independent experiments (mean $\pm \mathrm{SD}$ ). ${ }^{*} \mathrm{P}<0.05$ vs. TM + rAd-EGFP; ${ }^{* *} \mathrm{P}<0.01$ vs. TM + rAd-EGFP; ${ }^{\$} \mathrm{P}<0.05$ vs. control. SERCA2a, sarco/endoplasmic reticulum $\mathrm{Ca}^{2+}$-ATPase; NRCMs, neonatal rat cardiomyocytes; TM, tunicamycin; BiP, immunoglobulin heavy chain-binding protein; EGFP, enhanced green fluorescent protein.

and LDH leakage exhibited an increasing trend $(\mathrm{P}>0.05)$ compared with the TM + rAd-EGFP group, which suggested that the overexpression of SERCA2a induced EOR (Fig. 8).

Overexpression of SERCA2a decreases the level of nuclear phospho-p65 (Ser536). The increase in the NF- $\kappa \mathrm{B}$ p65 nuclear translocation and the attenuation of the upregulation of NF- $\kappa$ B p65 DNA-binding activity due to the overexpression of SERCA2a appeared paradoxical. To address this issue, the effects of overexpression of SERCA2a on post-translational modifications of $\mathrm{NF}-\kappa \mathrm{B}$ p 65 were further explored. Compared with that in the TM + rAd-EGFP group, the ratio

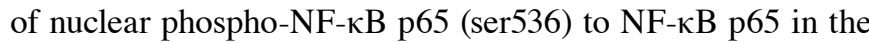
$\mathrm{TM}+$ rAd-SERCA2a group was significantly decreased by 59.6\% ( $\mathrm{P}<0.05$; Fig. 9).

\section{Discussion}

H9c2 cells lack NF- $\mathrm{BB}$ p50 expression (33); therefore, this cell line was not selected as the study object. TM blocks $\mathrm{N}$-linked glycosylation and is widely used to induce UPR. In this cell-based study, ERS-associated inflammation was induced by TM, thus preventing interference from tissue and circulating immune cells.
The present study demonstrated that TM induced a significant increase in the NF- $\mathrm{BB}$ DNA-binding activity and in the nuclear translocation of $\mathrm{NF}-\kappa \mathrm{B}$. The addition of the ERS protectant, TUDCA, prior to treatment with TM significantly attenuated the upregulation of DNA-binding activity of $\mathrm{NF}-\kappa \mathrm{B}$ and AP-1. These findings indicate that the cellular TM-induced ERS model was successfully constructed.

Hamid et al (33) revealed that in HF, persistent activation of NF- $\kappa \mathrm{B}$ p65 in myocytes aggravates ventricular remodeling by conferring pro-inflammatory, profibrotic and pro-apoptotic effects. It appears important to control the activation of NF- $\kappa \mathrm{B}$ in $\mathrm{HF}$. The UPR and $\mathrm{NF}-\kappa \mathrm{B}$ are interconnected through various mechanisms. In the present study, it was found that the overexpression of SERCA2a attenuated ERS and the activation of the IRE1 $\alpha$ signaling pathway in the NRCMs induced by $\mathrm{TM}$, resulting in the attenuation of the upregulation of $\mathrm{NF}-\kappa \mathrm{B}$ and AP-1 DNA-binding activities.

The accumulation of wild-type or misfolded proteins in the ER results in the release of $\mathrm{Ca}^{2+}$ from the ER. This leads to the generation of ROS, activating NF- $\kappa \mathrm{B}$. This process is called the EOR (34). Some viral proteins, such as the virion surface hemagglutinin (35), C-terminal truncation of the middle surface antigen from hepatitis B virus (36), adenovirus E3/19K protein (37) and human hepatitis C virus NS5A protein (38), 

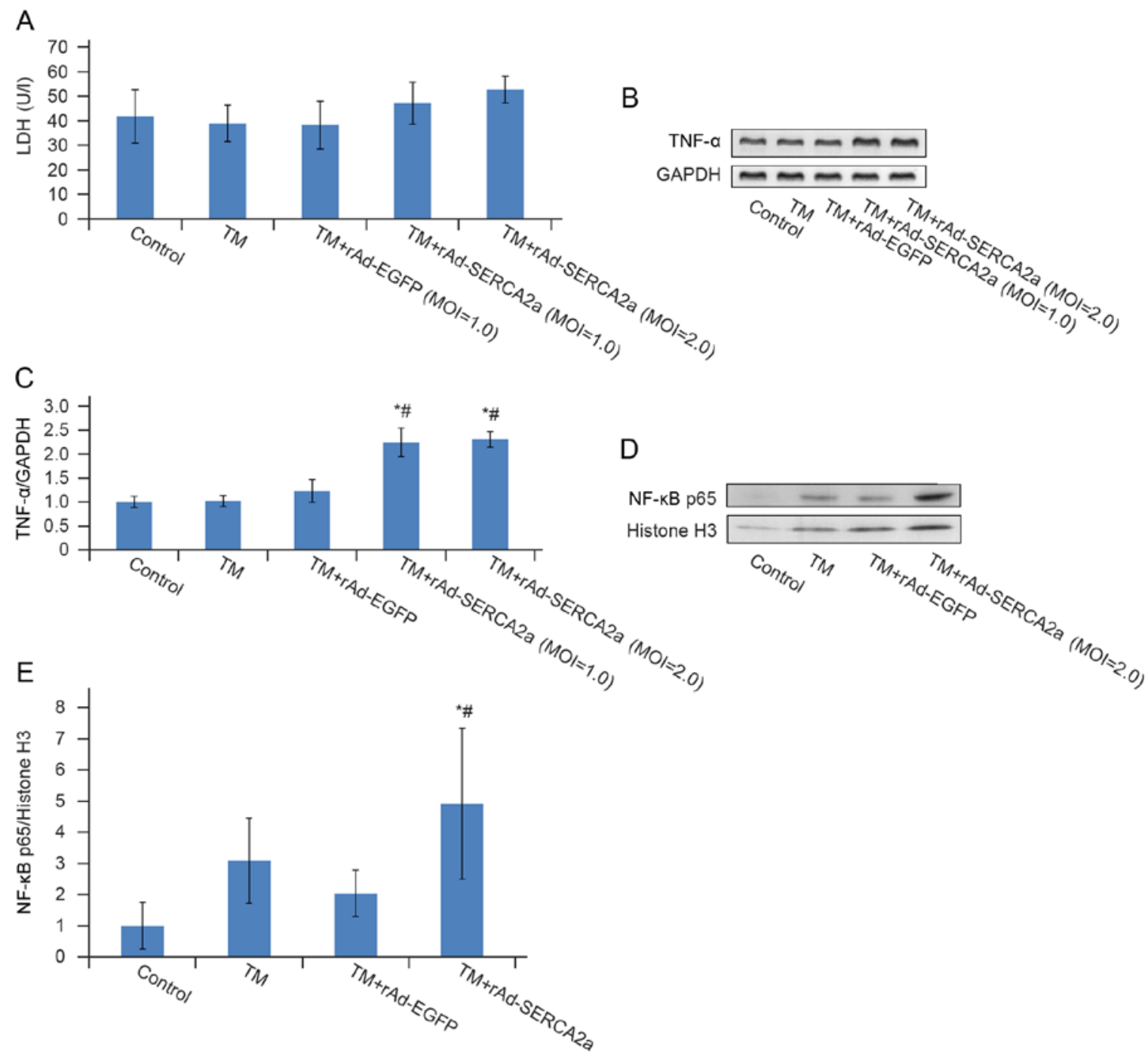

Figure 8. Effects of the overexpression of SERCA2a on the nuclear translocation of NF- $\mathrm{KB}$ p65 in NRCMs following treatment with TM for $24 \mathrm{~h}$. (A) Bar graph showing the effects of overexpression of SERCA2a on the level of leaked LDH in the culture medium following treatment with TM for $24 \mathrm{~h}$. (B) Images of RT-PCR products corresponding to TNF- $\alpha$ following agarose gel electrophoresis. (C) Bar graph showing the IODs of the TNF- $\alpha$ bands from (B) normalized to that of GAPDH. (D) Western blot bands corresponding to nuclear NF- $\mathrm{kB}$, with histone $\mathrm{H} 3$ as a nuclear internal control. (E) Bar graph showing the IODs of the NF- $\kappa B$ bands from (D) normalized to that of histone H3. Data represent three independent experiments (mean \pm SD). "P<0.05 vs. TM + rAd-EGFP; ${ }^{\sharp} \mathrm{P}<0.05$ vs. TM. SERCA2a, sarco/endoplasmic reticulum $\mathrm{Ca}^{2+}$-ATPase; NRCMs, neonatal rat cardiomyocytes; TM, tunicamycin; LDH, lactate dehydrogenase; IOD, integrated optical density; EGFP, enhanced green fluorescent protein; TNF- $\alpha$, tumor necrosis factor- $\alpha$.

can cause the EOR. The overexpression of SERCA2a in COS cells increases the calcium uptake rate; however, the overexpression of SERCA2a also induces cellular calcium overload and death (39). O'Donnell et al (32) proposed that in neonatal cardiomyocytes, the SR system was not well developed, and the SR volume was limited. A several-fold increase in SERCA within 2- to 3-day period can induce the dense accumulation of SERCA molecules in the limited SR space and leads to the disorder of membrane structure and function, resulting in perturbation of calcium homeostasis (32). These earlier findings indicate that exogenous expression of SERCA can cause EOR, although NF- $\kappa \mathrm{B}$ activation and TNF- $\alpha$ transcription have not been investigated. The window of MOIs between exogenous gene expression and production of cellular toxicity is narrower for the overexpression of SERCA than for EGFP. $\mathrm{Wu}$ et al found that at an MOI of $4 \mathrm{pfu} / \mathrm{cell}$, the overexpression of SERCA1 induced the loss of NRCMs and DNA fragmentation (40). O'Donnell et al (32) suggested that the optimal
MOI of adenoviral vector carrying wild-type SERCA1 is in the range of 2 to $4 \mathrm{pfu} / \mathrm{cell}$ in NRCMs. This titer increased SERCA activity by $>2$-fold and enhanced the kinetics of $\mathrm{Ca}^{2+}$ transients.

The present study identified $2 \mathrm{pfu} / \mathrm{cell}$ as the preferred MOI based on the expression level of exogenous SERCA2a, cell viability and $\mathrm{LDH}$ leakage, thus minimizing the cytopathic effects. However, at this MOI, the detachment of cells can still be observed under an inverted microscope. It was found that the nuclear translocation of NF- $\mathrm{NB}$ p 65 in the $\mathrm{TM}+\mathrm{rAd}-\mathrm{SERCA} 2 \mathrm{a}$ group was significantly increased following treatment with TM compared with that in the TM + rAd-EGFP group, which was consistent with the occurrence of the EOR.

However, the mechanisms through which the accumulation of proteins in the ER membrane increase $\mathrm{Ca}^{2+}$ permeability remain unclear. Pahl (34) proposed that the accumulation of membrane proteins may impair SERCA function, or the $\mathrm{Ca}^{2+}$ permeability of the ER membrane may be aggravated due to 


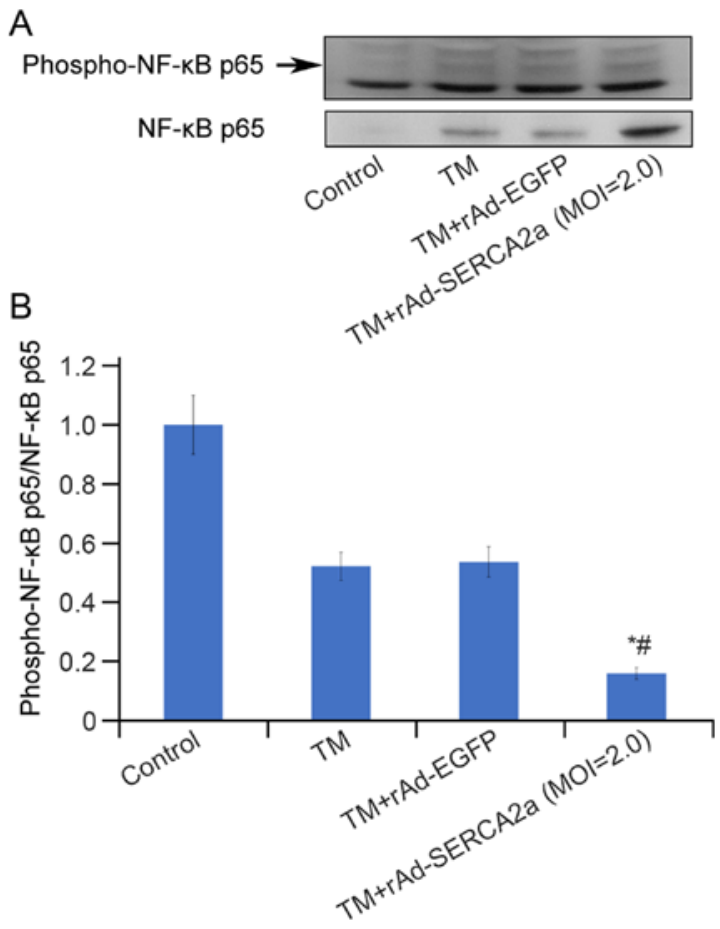

Figure 9. Effects of the overexpression of SERCA2a on the nuclear level of phospho-NF- $\mathrm{B}$ p65 (ser536) in NRCMs following treatment with TM for $24 \mathrm{~h}$. (A) Western blot bands corresponding to nuclear phospho-NF- $\mathrm{kB}$ p65 (ser536). Arrow indicates the position of phospho-NF-kB p65 (ser536) band. (B) Bar graph showing the ratio of the IODs of bands corresponding to the nuclear phospho-NF- $\mathrm{B}$ p65 (ser536) from (A) to that of NF- $\mathrm{kB}$ p65. Three independent experiments were performed (mean $\pm \mathrm{SD}$ ). ${ }^{*} \mathrm{P}<0.01 \mathrm{vs}$ $\mathrm{TM}+$ rAd-EGFP; ${ }^{\mathrm{P}}<0.01$ vs. TM. SERCA2a, sarco/endoplasmic reticulum $\mathrm{Ca}^{2+}$-ATPase; NRCMs, neonatal rat cardiomyocytes; TM, tunicamycin; IOD, integrated optical density.

an increase in the protein-to-lipid ratio. As earlier cell-based studies have demonstrated that the overexpression of SERCA2a can enhance its pump function, the latter possibility is more reasonable in the case of overexpression of SERCA2a-induced EOR.

$\mathrm{Hu}$ et al (41) confirmed that the production of TNF- $\alpha$ induced by ER stress was dependent on IRE1 $\alpha$ and NF- $\kappa \mathrm{B}$. The inhibition of the TNF receptor 1 signaling pathway significantly decreased ER stress-associated cell death (41). Hamid et al (42) demonstrated that TNFR1 augmented the activation of $\mathrm{NF}-\kappa \mathrm{B}$ in $\mathrm{H} 9 \mathrm{c} 2$ cells, and the pro-apoptotic effects of $\mathrm{NF}-\kappa \mathrm{B}$ overexpression required TNF elaboration and concomitant TNFR1 signaling. The present study demonstrated an increase in TNF- $\alpha$ transcription in the group overexpressing SERCA2a (Fig. 8), and it was thus hypothesized that EOR induced $N F-\kappa B$ p65 activation, which in turn induced an increase in TNF- $\alpha$ transcription. The transcription level of TNF- $\alpha$ was not significantly altered following TM treatment in the TM group, which may be due to IRE1-dependent decay of mRNA (RIDD) induced by ERS. It would thus be ideal to perform real-time fluorescent quantitative PCR at different time points to further verify this finding.

In view of the paradox between the increase in NF- $\mathrm{B}$ nuclear translocation and the attenuation of the upregulation of NF- $\kappa$ B DNA-binding activity, it was hypothesized that different post-translational modifications may account for this issue. RelA is phosphorylated at Ser536 by IKK $\beta$, IKK $\alpha$,
IKK $\varepsilon, N F-\kappa B$ activating kinase and RSK1. The stimulatory modifications of RelA enhance the transcriptional activity and capability of interaction with coactivators, such as histone acetyltransferase p300 (p300) and CREB-binding protein (CBP) (43). p300 and CBP acetylate RelA at several sites. Acetylation of K310 is necessary for complete transcriptional activity of NF- $\mathrm{B}$. The acetylation of K221 increases the DNA-binding affinity of RelA for $\kappa \mathrm{B}$ sites. The present exploratory study revealed a reduction in the level of phosphorylated P65 (Ser536) in the group overexpressing SERCA2a; however, the details of further post-translational modifications warrant further investigations. NF- $\kappa \mathrm{B}$ luciferase reporter assays should be helpful in clarifying the effects of the overexpression of SERCA2a on the transcriptional activity of NF- $\kappa \mathrm{B}$.

Sensitivity to subsequent TNF stimulation is lessened with pre-exposure to TNF, which is known as the 'TNF tolerance phenomenon'. Zwergal et al (44) demonstrated that CCAAT-enhancer-binding proteins $(\mathrm{C} / \mathrm{EBP})$ is necessary for the inhibition of $\mathrm{NF}-\kappa \mathrm{B}$ induced transcription in TNF-tolerant cells, which is mediated by the inhibition of $\mathrm{p} 65$ phosphorylation. Hu et al (41) revealed that ERS induced the downregulation of TRAF2 expression, leading to the attenuation of the TNF-induced activation of NF- $\kappa \mathrm{B}$ and JNK.

The studies by Kitamura (45), and Nakajima and Kitamura (46) reported that preceding ERS may attenuate the subsequent activation of NF- $\kappa \mathrm{B}$ by inflammatory cytokines and reviewed several possibilities. ERS can induce the selective degradation of TRAF2 (a key component involved in the TNF signaling), thereby inhibiting NF- $\kappa \mathrm{B}$ activation by TNF- $\alpha$. ERS can also induce the expression of $\mathrm{C} / \mathrm{EBP} \beta$, which interacts with the NF- $\kappa \mathrm{B}$ p65 subunit. The $\mathrm{C} / \mathrm{EBP} \beta-\mathrm{p} 65$ complexes contribute to the inhibition of activation of $\mathrm{NF}-\kappa \mathrm{B}$ by cytokines. In addition, ERS can induce the production of alpha induced protein 3 (A20), I $\mathrm{B} \alpha$, GRP78, and NO and dephosphorylation of Akt, which are involved in the suppression of NF- $\mathrm{KB}$ through various mechanisms.

In a preliminary experiment, it was found out that the expression level of TRAF2 was significantly reduced in the group overexpressing SERCA2a (data not shown); however, further repeated experiments are required to confirm this conclusion. It was hypothesized that the preceding EOR induced by accumulation of exogenous SERCA2a in sarcoplasmic reticulum might precondition the cells against subsequent TM-induced upregulation of $N F-\kappa B$ and AP-1 DNA-binding activities. Further studies to investigate C/EBP-p65 complexes and TRAF2 are required to substantiate this view.

It remains unclear as to whether EOR induced by SERCA2a overexpression was involved in alleviating ERS-related apoptosis in the present study. As it is well known that the increased SERCA2a expression can maintain calcium homeostasis and attenuate ERS, it could not be determined whether EOR can precondition the NRCMs against subsequent ERS-induced apoptosis. It is best to include another group to block $\mathrm{NF}-\kappa \mathrm{B}$ and/or $\mathrm{TNF} \alpha$ receptor signaling pathway to test this hypothesis.

Wu et al (40) revealed that the effects of adenoviral vector carrying SERCA1 on NRCMs and adult rat cardiomyocytes (ARCMs) were differed significantly. The infection of NRCMs at an MOI of $4 \mathrm{pfu} / \mathrm{cell}$ led to apoptosis. At an optimal MOI, 
the protein level of SERCA1 in NRCMs was 4-fold higher than that in the ARCMs, and the activity of $\mathrm{Ca}^{2+}$-ATPase increased by 4 -fold in the NRCMs, but only by 1.5 -fold in the ARCMs. It should be pointed out that since adenoviral vector carrying SERCA1 has no apoptotic effect on ARCMs (40), the findings of the present study using NRCMs cannot be extrapolated to explain the results of AAV1-SERCA2a gene therapy in the CUPID 2 study. In a previous rat pressure overload HF model, the intracoronary delivery of adenoviral vector carrying SERCA2 $a$ induced reductions in the serum levels of interleukin (IL)-1, IL-6 and TNF- $\alpha$; however, local inflammation of the heart was not investigated (47). To prevent the interference from EOR, it is better to undertake similar experiments in ARCMs.

There are some limitations associated with the present study. At the beginning of the experiment, it was not expected that the EOR would have such a profound impact on the experimental results. After obtaining the results, it was determined that the overexpression of SERCA2a leads to EOR, which would greatly interfere with the study of ERS-related inflammation. The authors thus aim to perform further research on ARCMs in the future. As shown in Fig. 9B, compared with the other three groups, the total p65 content in the nuclear compartment of untreated cardiomyocytes was minimal. When calculating the ratio of phosphorylated p65 to p65 in the control group, the ratio may become unreliable. IL-1 $\beta$, IL-6 and MCP-1 were detected in the culture medium supernatant in the present study; however, since these experiments were not repeated a sufficient number of times, the data were not presented. It is preferable to use more sensitive methods, such as reporter gene plasmid transfection to confirm the conclusions. In addition to caspase-12, it is preferable to evaluate more indicators related to apoptosis, such as caspase-3, poly(ADP-ribose) polymerase and Annexin V, in order to strengthen these conclusions.

In conclusion, in the cellular TM-induced ERS-associated inflammation model, the overexpression of SERCA2a in the NRCMs induced EOR, approximately two days prior to TM-induced UPR. The results suggested that the overexpression of SERCA2a had a 'double-edged sword' effect on ERS-associated inflammation. On the one hand, the overexpression of SERCA2a attenuated ERS and the activation of IRE1 $\alpha$ signaling pathway induced by TM, resulting in the attenuation of the upregulation of NF- $\mathrm{B}$ and AP-1 DNA-binding activities. However, on the other hand, the overexpression of SERCA2a induced EOR, leading to the further nuclear translocation of $\mathrm{NF}-\kappa \mathrm{B}$ and the transcription of TNF- $\alpha$. The preceding EOR may precondition the NRCMs against subsequent ERS-associated inflammation induced by TM. The findings of the present study may enhance the current understanding of the pros and cons of the overexpression of SERCA2a in the NRCMs and inspire the further exploration of the underlying mechanisms of the preconditioning effects induced by the EOR. Elucidating the aforementioned mechanisms may help to identify novel treatments for heart diseases in the future. Further studies performed using ARCMs are required to prevent the interference of the EOR, in which SERCA2a overexpression can be achieved through AAV1-SERCA2a transfection or constructing transgenic animal models.

\section{Acknowledgements}

Not applicable.

\section{Funding}

The present study was supported by the National Nature Science Foundation of China (grant no. 81170228).

\section{Availability of data and materials}

The datasets used and/or analyzed during the current study are available from the corresponding author on reasonable request.

\section{Authors' contributions}

XLu and XLi were involved in the conception of the study, applying for funds and revising the manuscript. ZQ, YQ and TT performed the experiments. ZQ prepared the draft of the manuscript. XLiu was involved in designing part of the study and revising the manuscript. ZQ and XLu confirm the authenticity of all the raw data. All authors have read and approved the final manuscript.

\section{Ethics approval and consent to participate}

All animal experiments were performed in accordance with the Guide for the Care and Use of Laboratory Animals (8th Edition, 2011) and the animal experimentation guidelines of the Chinese PLA General Hospital.

\section{Patient consent for publication}

Not applicable.

\section{Competing interests}

The authors declare that they have no competing interests.

\section{References}

1. WRITING GROUP MEMBERS; Lloyd-Jones D, Adams RJ, Brown TM, Carnethon M, Dai S, De Simone G, Ferguson TB, Ford E, Furie K, et al: Heart disease and stroke statistics-2010 Update: A report from the American Heart Association. Circulation 121: e46-e215, 2010.

2. Gwathmey JK, Copelas L, MacKinnon R, Schoen FJ, Feldman MD, Grossman W and Morgan JP: Abnormal intracellular calcium handling in myocardium from patients with end-stage heart failure. Circ Res 61: 70-76, 1987.

3. Hasenfuss G, Reinecke H, Studer R, Meyer M, Pieske B, Holtz J, Holubarsch C, Posival H, Just H and Drexler H: Relation between myocardial function and expression of sarcoplasmic reticulum $\mathrm{Ca}(2+)$-ATPase in failing and nonfailing human myocardium. Circ Res 75: 434-442, 1994.

4. Meyer M, Schillinger W, Pieske B, Holubarsch C, Heilmann C, Posival H, Kuwajima G, Mikoshiba K, Just H, Hasenfuss G, et al: Alterations of sarcoplasmic reticulum proteins in failing human dilated cardiomyopathy. Circulation 92: 778-784, 1995.

5. Hajjar RJ, Kang JX, Gwathmey JK and Rosenzweig A: Physiological effects of adenoviral gene transfer of sarcoplasmic reticulum calcium ATPase in isolated rat myocytes. Circulation 95: 423-429, 1997. 
6. Kawase Y, Ly HQ, Prunier F, Lebeche D, Shi Y, Jin H, Hadri L, Yoneyama R, Hoshino K, Takewa Y, et al: Reversal of cardiac dysfunction after long-term expression of SERCA2a by gene transfer in a pre-clinical model of heart failure. J Am Coll Cardiol 51: 1112-1119, 2008.

7. He H, Giordano FJ, Hilal-Dandan R, Choi DJ, Rockman HA, McDonough PM, Bluhm WF, Meyer M,Sayen MR,Swanson E, et al: Overexpression of the rat sarcoplasmic reticulum $\mathrm{Ca}^{2+}$ ATPase gene in the heart of transgenic mice accelerates calcium transients and cardiac relaxation. J Clin Invest 100: 380-389, 1997.

8. Baker DL, Hashimoto K, Grupp IL, Ji Y, Reed T, Loukianov E, Grupp G, Bhagwhat A, Hoit B, Walsh R, et al: Targeted overexpression of the sarcoplasmic reticulum $\mathrm{Ca}^{2+}$-ATPase increases cardiac contractility in transgenic mouse hearts. Circ Res 83 1205-1214, 1998.

9. Dillmann WH: Influences of increased expression of the $\mathrm{Ca}^{2+}$ ATPase of the sarcoplasmic reticulum by a transgenic approach on cardiac contractility. Ann N Y Acad Sci 853: 43-48, 1998

10. Maier LS, Wahl-Schott C, Horn W, Weichert S, Pagel C, Wagner S, Dybkova N, Müller OJ, Näbauer M, Franz WM and Pieske B: Increased SR $\mathrm{Ca}^{2+}$ cycling contributes to improved contractile performance in SERCA2a-overexpres sing transgenic rats. Cardiovasc Res 67: 636-646, 2005.

11. Müller OJ, Lange M, Rattunde H, Lorenzen HP, Müller M, Frey N, Bittner C, Simonides W, Katus HA and Franz WM: Transgenic rat hearts overexpressing SERCA2a show improved contractility under baseline conditions and pressure overload Cardiovasc Res 59: 380-389, 2003.

12. Suarez J, Gloss B, Belke DD, Hu Y, Scott B, Dieterle T, Kim YK, Valencik ML, McDonald JA, and Dillmann WH: Doxycycline inducible expression of SERCA2a improves calcium handling and reverts cardiac dysfunction in pressure overload-induced cardiac hypertrophy. Am J Physiol Heart Circ Physiol 287: H2164-H2172, 2004.

13. del Monte F, Williams E, Lebeche D, Schmidt U, Rosenzweig A, Gwathmey JK, Lewandowski ED, and Hajjar RJ: Improvement in survival and cardiac metabolism after gene transfer of sarcoplasmic reticulum $\mathrm{Ca}(2+)$-ATPase in a rat model of heart failure. Circulation 104: 1424-1429, 2001.

14. Sakata S, Lebeche D, Sakata N, Sakata Y, Chemaly ER, Liang LF Tsuji T, Takewa Y, del Monte F, Peluso R, et al: Restoration of mechanical and energetic function in failing aortic-banded rat hearts by gene transfer of calcium cycling proteins. J Mol Cell Cardiol 42: 852-861, 2007

15. Mitsuyama S, Takeshita D, Obata K, Zhang GX and Takaki M Left ventricular mechanical and energetic changes in long-term isoproterenol-induced hypertrophied hearts of SERCA2a transgenic rats. J Mol Cell Cardiol 59: 95-106, 2013.

16. Davia K, Bernobich E, Ranu HK, del Monte F, Terracciano CM, MacLeod KT, Adamson DL, Chaudhri B, Hajjar RJ and Harding SE: SERCA2A overexpression decreases the incidence of aftercontractions in adult rabbit ventricular myocytes. J Mol Cell Cardiol 33: 1005-1015, 2001.

17. Cutler MJ, Wan X, Plummer BN, Liu H, Deschenes I, Laurita KR, Hajjar RJ and Rosenbaum DS: Targeted sarcoplasmic reticulum $\mathrm{Ca} 2+$ ATPase 2a gene delivery to restore electrical stability in the failing heart. Circulation 126: 2095-2104, 2012.

18. Lyon AR, Bannister ML, Collins T, Pearce E, Sepehripour AH Dubb SS, Garcia E, O'Gara P, Liang L, Kohlbrenner E, et al: SERCA2a gene transfer decreases sarcoplasmic reticulum calcium leak and reduces ventricular arrhythmias in a model of chronic heart failure. Circ Arrhythm Electrophysiol 4: 362-372, 2011.

19. Prunier F, Kawase Y, Gianni D, Scapin C, Danik SB, Ellinor PT, Hajjar RJ and Del Monte F: Prevention of ventricular arrhythmias with sarcoplasmic reticulum $\mathrm{Ca}^{2+}$ ATPase pump overexpression in a porcine model of ischemia reperfusion. Circulation 118 : 614-624, 2008

20. del Monte F, Lebeche D, Guerrero JL, Tsuji T, Doye AA, Gwathmey JK and Hajjar RJ: Abrogation of ventricular arrhythmias in a model of ischemia and reperfusion by targeting myocardial calcium cycling. Proc Natl Acad Sci USA 101: 5622-5627, 2004

21. Cutler MJ, Wan X, Laurita KR, Hajjar RJ and Rosenbaum DS Targeted SERCA2a gene expression identifies molecular mechanism and therapeutic target for arrhythmogenic cardiac alternans. Circ Arrhythm Electrophysiol 2: 686-694, 2009.

22. Hadri L, Bobe R, Kawase Y, Ladage D, Ishikawa K, Atassi F, Lebeche D, Kranias EG, Leopold JA, Lompré AM, et al: SERCA2a gene transfer enhances eNOS expression and activity in endothelial cells. Mol Ther 18: 1284-1292, 2010.
23. Jaski BE, Jessup ML, Mancini DM, Cappola TP, Pauly DF, Greenberg B, Borow K, Dittrich H, Zsebo KM and Hajjar RJ: Calcium upregulation by percutaneous administration of gene therapy in cardiac disease (CUPID Trial), a first-in-human phase 1/2 clinical trial. J Card Fail 15: 171-181, 2009.

24. Jessup M, Greenberg B, Mancini D, Cappola T, Pauly DF, Jaski B, Yaroshinsky A, Zsebo KM, Dittrich H and Hajjar RJ; Calcium Upregulation by Percutaneous Administration of Gene Therapy in Cardiac Disease (CUPID) Investigators: Calcium upregulation by percutaneous administration of gene therapy in cardiac disease (CUPID) A phase 2 trial of intracoronary gene therapy of sarcoplasmic reticulum Ca2+-ATPase in patients with advanced heart failure. Circulation 124: 304-313, 2011.

25. Zsebo K, Yaroshinsky A, Rudy JJ, Wagner K, Greenberg B, Jessup $M$ and Hajjar RJ: Long-term effects of AAV1/SERCA2a gene transfer in patients with severe heart failure analysis of recurrent cardiovascular events and mortality. Circ Res 114: 101-108, 2014.

26. Greenberg B, Butler J, Felker GM, Ponikowski P, Voors AA, Desai AS, Barnard D, Bouchard A, Jaski B, Lyon AR, et al: Calcium upregulation by percutaneous administration of gene therapy in patients with cardiac disease (CUPID 2): A randomised, multinational, double-blind, placebo-controlled, phase 2b trial. Lancet 387: 1178-1186, 2016.

27. Zhang K and Kaufman RJ: From endoplasmic-reticulum stress to the inflammatory response. Nature 454: 455-462, 2008.

28. Schmitz ML, Shaban MS, Albert BV, Goekcen A and Kracht M: The crosstalk of endoplasmic reticulum (ER) stress pathways with NF- $\kappa \mathrm{B}$ : Complex mechanisms relevant for cancer, inflammation and infection. Biomedicines 6: 58, 2018.

29. Liu XH, Zhang ZY, Andersson KB, Husberg C, Enger UH, Ræder MG, Christensen G and Louch WE: Cardiomyocytespecific disruption of Serca2 in adult mice causes sarco(endo) plasmic reticulum stress and apoptosis. Cell Calcium 49: 201-207, 2011.

30. Xin W, Lu X, Li X, Niu K and Cai J: Attenuation of endoplasmic reticulum stress-related myocardial apoptosis by SERCA2a gene delivery in ischemic heart disease. Mol Med 17: 201-210, 2011.

31. National Research Council (U.S.): Committee for the Update of the Guide for the Care and Use of Laboratory Animals. Guide for the Care and Use of Laboratory Animals. 8th edition. Washington DC. National Academies Press, 2011.

32. O'Donnell JM, Sumbilla CM, Ma H, Farrance IK, Cavagna M, Klein MG and Inesi G: Tight control of exogenous SERCA expression is required to obtain acceleration of calcium transients with minimal cytotoxic effects in cardiac myocytes. Circ Res 88: 415-421, 2001.

33. Hamid T, Guo SZ, Kingery JR, Xiang X, Dawn B and Prabhu SD: Cardiomyocyte NF- $\kappa \mathrm{B}$ p 65 promotes adverse remodelling, apoptosis, and endoplasmic reticulum stress in heart failure. Cardiovasc Res 89: 129-138, 2011.

34. Pahl HL: Signal transduction from the endoplasmic reticulum to the cell nucleus. Physiol Rev 79: 683-701, 1999.

35. Pahl HL and Baeuerle PA: Expression of influenza virus hemagglutinin activates transcription factor NF-kappa B. J Virol 69: 1480-1484, 1995

36. Meyer M, Caselmann WH, Schluter V, Schreck R, Hofschneider PH and Baeuerle PA: Hepatitis B virus transactivator MHBst: Activation of NF-kappa B, selective inhibition by antioxidants and integral membrane localization. EMBO J 11 : 2991-3001, 1992.

37. Pahl HL, Sester M, Burgert HG and Baeuerle PA: Activation of transcription factor NF-kappaB by the adenovirus E3/19K protein requires its ER retention. J Cell Biol 132: 511-522, 1996.

38. Gong G, Waris G, Tanveer R and Siddiqui A: Human hepatitis $\mathrm{C}$ virus NS5A protein alters intracellular calcium levels, induces oxidative stress, and activates STAT-3 and NF-kappa B. Proc Natl Acad Sci USA 98: 9599-9604, 2001.

39. Ma TS: Sarcoplasmic reticulum calcium ATPase overexpression induces cellular calcium overload and cell death. Ann NY Acad Sci 853: 325-328, 1998 .

40. Wu GM, Long XL and Marin-Garcia J: Adenoviral SERCA1 overexpression triggers an apoptotic response in cultured neonatal but not in adult rat cardiomyocytes. Mol Cell Biochem 267: $123-132,2004$

41. Hu P, Han Z, Couvillon AD, Kaufman RJ and Exton JH: Autocrine tumor necrosis factor alpha links endoplasmic reticulum stress to the membrane death receptor pathway through IRE1 alpha-mediated NF-kappa B activation and down-regulation of TRAF2 expression. Mol Cell Biol 26: 3071-3084, 2006. 
42. Hamid T, Gu Y, Ortines RV, Bhattacharya C, Wang G, Xuan YT and Prabhu SD: Divergent tumor necrosis factor receptor-related remodeling responses in heart failure role of nuclear factor-kappa B and inflammatory activation. Circulation 119: 1386-1397, 2009.

43. Perkins ND: Post-translational modifications regulating the activity and function of the nuclear factor kappa B pathway. Oncogene 25: 6717-6730, 2006.

44. Zwergal A, Quirling M, Saugel B, Huth KC, Sydlik C, Poli V, Neumeier D, Ziegler-Heitbrock HW and Brand K: C/EBP beta blocks p65 phosphorylation and thereby NF-kappa B-mediated transcription in TNF-tolerant cells. J Immunol 177: 665-672, 2006.

45. Kitamura M: Biphasic, bidirectional regulation of NF-kappaB by endoplasmic reticulum stress. Antioxid Redox Signal 11: 2353-2364, 2009.
46. Nakajima S and Kitamura M: Bidirectional regulation of NF- $\kappa \mathrm{B}$ by reactive oxygen species: A role of unfolded protein response. Free Radic Biol Med 65: 162-174, 2013.

47. Gupta D, Palma J, Molina E, Gaughan JP, Long W, Houser S and Macha M: Improved exercise capacity and reduced systemic inflammation after adenoviral-mediated SERCA-2a gene transfer. J Surg Res 145: 257-265, 2008.

(i) $\ominus$ This work is licensed under a Creative Commons Attribution-NonCommercial-NoDerivatives 4.0 International (CC BY-NC-ND 4.0) License. 